\title{
THE CONTRACEPTIVE MANDATE: COMPELLING INTEREST OR IDEOLOGY?
}

\author{
Karen A. Jordan, Professor of Law at the University of Louisville School of Law
}

Abstract: In the wake of the administrative rule requiring employee health benefit plans to cover contraceptive services, many employers are pursuing religious liberty claims against the federal government. In claims under the Religious Freedom Restoration Act, a prima facie showing by a plaintiff that a federal law substantially burdens the exercise of religion shifts the burden to the government to justify the burden by showing that the law is the least restrictive means of advancing a compelling governmental interest. This article focuses on the compelling interest prong of the government's burden. The text of RFRA and judicial gloss make clear that the government's burden of proof is not insubstantial: the government must demonstrate, with probative and persuasive evidence, that applying the law to the person challenging it in fact furthers a compelling governmental interest. In the lawsuits, courts and litigants have tended to focus on the exemptions built into the coverage mandate, but the more significant weakness in the government's case relates to the limited value of the evidence supposedly showing that the contraceptive mandate furthers the relevant compelling interest. The article demonstrates that the relevant compelling interest is narrower than the interests pointed to by the government in the litigation, and that evidence relied on by the government to show that the mandate furthers the compelling interest lacks probative and persuasive value.

More specifically, the compelling interest is the interest in providing coverage for preventive services needed to protect women's health, and the evidence relied on by the government in the litigation and in the rulemaking process that purportedly shows that contraceptive services promote women's health suffers from a variety of shortcomings. Congress envisioned that reliance on expert advisors who conducted rigorous risk/benefit assessments would ensure that services would be included in the mandate only if they genuinely promote women's health and are not merely popular services. The agency confirmed the importance of a risk/benefit assessment as part of the rulemaking process, and delegated the task to the Institute of Medicine (IOM). The government points to the resulting 2011 IOM recommendation as evidence justifying the mandate's burden on the challengers' exercise of religion. However, scrutiny of the methodology used by IOM in the recommendation process and its application to contraceptive services, and scrutiny of sources relied on by IOM in producing its recommendation, reveals obvious gaps, omissions, and logical shortcomings that seriously undermine the recommendation's evidentiary value. Family planning is important for women's health, but the evidence does not support the proposition that contraceptives are necessary for safe and effective family planning, and thus does not support the proposition that contraceptives are necessary for women's health. Scrutiny of the 2011 IOM recommendation and the sources relied 
[Vol. 41:1

on by IMO show that ideology was the driving force behind the contraceptive mandate and, under RFRA, promotion of ideology will not satisfy the government's burden. 


\section{THE CONTRACEPTIVE MANDATE: COMPELLING INTEREST OR IDEOLOGY?}

As part of the administration's implementation of federally mandated health insurance for preventive services, regulations issued in 2012 have triggered numerous lawsuits alleging religious liberty claims. ${ }^{1}$ The regulations were designed to implement a congressional directive aimed at improving women's health by enhancing insurance coverage for preventive health care and screening. ${ }^{2}$ Developed largely under the mantle of the Department of Health and Human Services, ${ }^{3}$ the regulations require health insurers and group health plans provided by employers to cover, without cost-sharing, items and services found through the administrative process to be "preventive services." The items HHS designated as women's preventive services include many non-controversial services, but the mandate includes coverage without cost sharing for all FDA-approved contraceptive drugs, and female sterilization services. ${ }^{4}$ This aspect of the mandate - referred to as the contraceptive mandate - has been the basis for religious liberty challenges because it requires many persons who find the services to be immoral to nonetheless facilitate use of the services. ${ }^{5}$

1. See Group Health Plans and Health Insurance Issuers Relating to Coverage of Preventative Services Under the Patient Protection and Affordable Care Act, 77 Fed. Reg. 8725-30 (Feb. 15, 2012) [hereinafter Preventative Services Coverage for Plans and Issuers] (exempting various health plans and health insurance coverage sponsored by certain religious employers from having to cover some preventative health services). The regulations were promulgated pursuant to the Patient Protection and Affordable Care Act (the "ACA"). Id. See also Patient Protection and Affordable Care Act, Pub. L. No. 111-148, 124 Stat. 119 (2010).

2. The ACA amends the Public Health Service Act by inserting a new provision requiring group health plans and health insurance issuers to provide insurance without cost sharing for, inter alia, (1) services rated " $\mathrm{A}$ " or " $\mathrm{B}$ " in the current recommendations of the United States Preventive Services Task Force ("USPSTF") and, (2) with respect to women, such additional preventative care and screenings as provided for in comprehensive guidelines supported by the Health Resources and Services Administration. See ACA § 2713(a) (codified at 42 U.S.C. § 300gg-13).

3. The administrative rulemaking leading to the contraceptive mandate required involvement of three agencies: the Department of Treasury (via the IRS), the Department of Labor (specifically the Employee Benefits Security Administration ("EBSA")), and the Department of Health and Human Services ("HHS"). Preventative Services Coverage for Plans and Issuers, supra note 1. Reasons exist, however, for treating the regulation as being issued by HHS: the statutory text giving rise to the mandate creates a key role for the Health Resources and Services Administration ("HRSA") which is within HHS; and section 1001 of the ACA amends the Public Health Service Act by inserting a new section 2713 which is administered by HHS. See ACA § $2713(a)$.

4. See ACA § 2713(a). The services also include related education and counseling. Id. For a discussion of the process leading to the content of the women's preventative services, see infra notes 93-100 and accompanying text.

5. The contraceptive mandate is controversial for both religious and non-religious reasons. First, although responsible decision making regarding whether and when to conceive and bear children is legitimate, many believe it is wrong to engage in intentional acts that distort the nature of sexual activity by deliberately blocking the possibility of children. To many, such acts are inconsistent with God's plan for human love within marriage, and are acts that divert a person away from human flourishing. They are thus immoral actions. As discussed infra note 72 and accompanying text, the 
The agency recognized the mandate would raise religious liberty issues and included in the 2012 Final Rule an exemption for organizations falling within the regulation's definition of religious employer. The exemption, however, was exceedingly narrow,${ }^{6}$ and due to widespread objection the administration agreed to work to enlarge the exemption and delay implementation. ${ }^{7}$ But HHS did not revoke the mandate and the administrative rulemaking process has not yet provided redress for many employers with religious objections. 8 This scheme has created hardship for employers who believe compliance interferes with their exercise of religion and who do not fall within the exemption. Many of these non-exempt employers-generally Christian business owners who view contraceptive use as immoral - are asking courts to set aside the mandate on the grounds that it violates the free exercise rights created by the Religious Freedom Restoration Act (the "RFRA") and the First Amendment to the United States Constitution. ${ }^{9}$ The results thus far have been mixed, but some courts have found that the challengers have shown a likelihood of success. ${ }^{10}$

distortion is not necessary for family planning because non-contraceptive methods exist that effectively and safely allow responsible spacing of children. Second, sterilization and most contraceptive methods involve mutilation or distortion of the natural and healthy operation of the human reproductive system, see infra notes 202-21 and accompanying text, and several of them also have the potential to cause the destruction of a fertilized egg in the womb. The mandate requires insurance coverage without cost-sharing for the services and thus, given the way insurers fund coverage, requires people who view the services as immoral or a life-style choice to nonetheless shoulder the costs of the use of the services. The impact on objecting employers is more direct and substantial. Requiring them to provide insurance coverage is a more tangible cooperation in immoral acts by others.

6. The 2012 Final Rule limited the exemption to a religious employer that "(1) [h] as the inculcation of religious values as its purpose; (2) primarily employs persons who share its religious tenets; (3) primarily serves persons who share its religious tenets; and (4) is a nonprofit organization," such as a church, an integrated auxiliary of a church, conventions or associations of churches, or exclusively religious activities of a religious order. See Preventative Services Coverage for Plans and Issuers, 77 Fed. Reg. at 8726-27; see also Coverage of Certain Preventative Services Under the Affordable Care Act, 78 Fed. Reg. 39870, 39874 (July 2, 2013) (describing the exemption in the 2012 Final Rule).

7. The federal agencies issued guidance establishing a temporary safe harbor from enforcement of the mandate for certain group health plans of certain nonprofit organizations with religious objections. See Coverage of Certain Preventative Services Under the Affordable Care Act, 78 Fed. Reg. at 39871 (explaining the safe harbor).

8. The most recent Final Rule, issued July 2, 2013, eliminated the first three criteria listed in the 2012 definition of an exempt religious employer, but retained the limitation that the employer be a nonprofit organization such as a church, an integrated auxiliary of a church, conventions or associations of churches, or exclusively religious activities of a religious order. See id. at 39874. In a press release issued July 2, 2013, by the United States Conference of Catholic Bishops ("USCCB"), Cardinal Timothy Dolan explained that the 2013 Final Rule has not eliminated religious liberty concerns, especially for individuals and for-profit businesses: "We are concerned as pastors with the freedom of the Church as a whole - not just for the full range of its institutional forms, but also for the faithful in their daily lives - to carry out the mission and ministry of Jesus Christ." Press Release, U.S. Conference of Catholic Bishops, HHS Final Rule Still Requires Action In Congress, By Courts, Says Cardinal Dolan (July 3, 2013), available at http://www.usccb.org/news/2013/13-137.cfm.

9. See, e.g., Hobby Lobby Stores. v. Sebelius, 723 F.3d 1114 (10th Cir. 2013), cert. granted, 134 S.Ct. 678 (2013).

10. See, e.g., Korte v. Sebelius, 735 F.3d 654 (7th Cir. 2013); Gilardi v. U.S. Dep't of Health and Human Services, 733 F.3d 1208 (D.C. Cir. 2013); Hobby Lobby Stores, 723 F.3d 1114. But see Autocam Corp. v. Sebelius, 730 F.3d 618 (6th Cir. 2013) (affirming district court's denial of preliminary injunction); Conestoga Wood Specialties Corp. v. Sec'y of U.S. Dep't of Health and Human Services, 724 
In deciding the issue of likelihood of success, courts have tended to focus on the RFRA claim. ${ }^{11}$ This is because Congress' primary purpose for enacting the RFRA was to overrule the Supreme Court's decision to eliminate the substantial burden and compelling interest analyses in constitutional free exercise challenges as to many neutral and otherwise valid laws of general applicability. ${ }^{12}$ If the RFRA applies, strict scrutiny is triggered if a plaintiff presents a prima facie case showing that a federal law substantially burdens the exercise of religion. ${ }^{13}$ A prima facie showing shifts the burden to the government, requiring it to justify the burden by showing that the law is the least restrictive means of advancing a compelling governmental interest. ${ }^{14}$

In the lawsuits, whether the RFRA applies has presented important threshold issues. ${ }^{15}$ If the Court sides with the challengers, however, the focus shifts to the substantial burden and compelling interest analyses and, to many, it seems the challengers most certainly will be able to make a prima facie showing. ${ }^{16}$ The real issue, then, if the RFRA applies, is whether the gov-

F.3d 377 (3d Cir. 2013), cert. granted, 134 S.Ct. 678 (Nov. 26, 2013) (affirming district court's denial of a preliminary injunction). The lawsuits have followed a predictable path. The initial flurry of cases involved motions by HHS to dismiss the actions, due to lack of standing and concerns about ripeness. The more recent cases have involved motions for preliminary injunctions, when the motions have been denied, interlocutory appeals of the denial and a motion for injunction pending appeal. Whether preliminary or pending injunctive relief should be granted involves a multi-factored assessment. A key factor in the analysis is the plaintiff's "likelihood of success of the merits."

11. See, e.g., Hobby Lobby Stores, 723 F.3d 1114; Autocam Corp., 730 F. 3d 618; Conestoga Wood Specialties Corp., 724 F.3d 377. The RFRA is set out at 42 U.S.C. $\$ \S 2000 \mathrm{bb}-\mathrm{bb}-4$.

12. See 42 U.S.C. $\$ 2000 \mathrm{bb}(\mathrm{b})(1)$ (2014); see also Dep't of Human Res. of Oregon v. Smith, 494 U.S. 872 (1990). In Smith, the majority left open the door to use of the analysis in cases that involve free exercise in conjunction with other constitutional protections, such as freedom of speech and the press, or parental rights. See id. at 881-82.

13. See 42 U.S.C. § $2000 \mathrm{bb}-1$ (a). The RFRA provides that, ordinarily, the "Government shall not substantially burden a person's exercise of religion." Id. Strict scrutiny is triggered if a plaintiff presents a prima facie case showing that a federal law substantially burdens the exercise of religion.

14. A prima facie showing shifts the burden to the government, requiring it to justify the burden by showing that the law furthers a compelling governmental interest, see 42 U.S.C. \$2000bb-1(b)(1), and is the least restrictive means of advancing that compelling governmental interest, see 42 U.S.C. $\S$ $2000 \mathrm{bb}(\mathrm{b})(2)$. RFRA itself did not distinguish between federal and state laws, see 42 U.S.C. 2000bb3(a), but the Court struck it down as applied to state laws in City of Boerne v. Flores, 521 U.S. 507 (1997).

15. The lawsuits have been brought by Christian persons operating a "non-religious" business typically a for-profit corporation - that provides a group health plan to its employees. As such, threshold questions are whether business owners who use the corporate form are entitled to free exercise protection, and whether day-to-day activities involved in running a for-profit business can constitute the exercise of religion. Thus far in the litigation, the government has focused its attention primarily on these threshold issues, specifically, on arguments that neither the individual plaintiffs nor their business organizational are "persons" capable of stating RFRA or constitutional free exercise claims. That strategy makes some sense. Resolution of the questions is far from predictable, given that Supreme Court precedent does not squarely address the issue and that several lower courts (and several dissenting judges) have sided with the government. But, the arguments supporting this conclusion seem rather technical and inconsistent with Congress' purpose in enacting RFRA, and, as noted, some courts have found in favor of the challengers. Given the circuit splits, the issue ultimately will be resolved by the Supreme Court.

16. The government's key argument is that the mandate does not pose a substantial burden because the impact on the business owners is too attenuated. Some lower courts have adopted this line 
ernment can satisfy its burden of justifying the burden on the exercise of religion resulting from the mandate. This article focuses on the "compelling interest" prong of the government's burden. It is important to focus on this prong because the text of the RFRA and the judicial gloss make clear that the government's burden of proof here is substantial, and, in the litigation thus far, the government has made little effort to satisfy its burden. The government must demonstrate, with probative and persuasive evidence, that it has identified the relevant compelling interest and that applying the law to the particular person challenging the law in fact furthers that interest. ${ }^{17}$ Because Supreme Court precedent suggests that the existence of exemptions considerably weakens the government's case, the litigants and courts have focused attention on the exemptions already built into the general coverage mandate as to women's preventive services and the contraceptive mandate in particular. ${ }^{18}$ However, the more significant weakness in the government's case relates to the limited probative and persuasive value of the evidence supposedly showing that the contraceptive mandate furthers the relevant compelling interest.

This article focuses attention on several aspects of the government's evidence that render the evidence of limited value. The article first explains the government's burden under the RFRA, and the arguments and evidence relied on in the lawsuits challenging the mandate. The article identifies the relevant compelling interest, and then provides an in-depth analysis of the evidence relied on by the government in the litigation, as well as the fuller range of evidence relevant to the government's case. Scrutiny of the evidence

of reasoning. This perspective is flawed, however, because it invites judges to decide what the Supreme Court has recognized to be a religious question. Rather, as clarified by Justice O'Connor in Smith, whether a burden is constitutionally significant hinges on the coercive pressure imposed by a law conflicting with faith: the question is whether the law compels a choice, whether by way of criminalizing the act, exacting penalties, or withholding benefits. See Smith, 494 U.S. at 899, 903-04 ( $\mathrm{O}^{\prime}$ Connor, J., concurring). The majority read $\mathrm{O}^{\prime}$ Connor's opinion as requiring an inquiry into the "centrality" of the religious activity at issue. See id. at 887 n. 4 . However, this is not an accurate reading of the concurring opinion. But see Korte v. Sebelius, 735 F.3d 654, 705-14 (7th Cir. 2013) (Rovner, J., dissenting) (arguing that a "coercion-only" test is an invention of the Tenth Circuit).

In the case of the contraceptive mandate, the legal analysis becomes reasonably straightforward. For various reasons, many Christians believe the use of contraceptive services is immoral and inconsistent with God's plan for human love in marriage. They also believe providing insurance coverage for use of contraceptive services is wrongful cooperation with an immoral act by another. These are sincerely held beliefs. In the litigation, there is no dispute as to these facts. The analysis therefore turns on the quantum of pressure being exerted by way of the mandate. Yet, there also is no dispute as to the penalties the objecting business owners face for non-compliance with the mandate: to the extent an employer provides a health plan, it can be fined $\$ 100$ per employee per day if the plan does not meet the contraceptive mandate. If an employer stops offering a health plan, it can be fined $\$ 2,000$ per employee, per year. On their face, the penalties are significant. As applied, they can be staggering. For example, Hobby Lobby has over 13,000 employees, and the majority opinion thus pointed out that the corporation faced penalties of more than $\$ 1.3$ million per day for non-compliance (\$475 million per year); or \$26 million per year if it stopped providing health insurance. See Hobby Lobby, 723 F.3d at 1140-41. Given these facts, the majority aptly noted: "it is difficult to characterize the pressure as anything but substantial." Id. at 1140; see also Gilardi, 733 F.3d at 1217-18.

17. See infra notes 19-23 and accompanying text.

18. See infra notes 55-59 and accompanying text. 
reveals its limited probative and persuasive value, and supports the characterization provided in an amicus curiae brief, namely, that the government's case "is based on a chain of presumed causes and effects, and the evidence supporting each link is attenuated, ambiguous, disputed, or non-existent."19 The shortcomings are of such a magnitude that it becomes reasonable to assert that ideology rather than evidence was the driving force behind the contraceptive mandate: an ideology so deeply held that genuine attention to women's health has been overshadowed. In a RFRA challenge, it is not sufficient to show that the law furthers ideology.

\section{THE GOVERNMENT'S EVIDENTIARY BURDEN UNDER THE RFRA}

Statutory text and judicial gloss by the Supreme Court clarify that the government's burden under the RFRA is not insubstantial. Once a challenger has made a prima facie showing that a federal law substantially burdens the exercise of religion, the burden shifts to the government to prove the law furthers a "compelling governmental interest" through the "least restrictive means." 20 More particularly, as to the first prong of the analysis, the RFRA provides that "Government may substantially burden a person's exercise of religion only if it demonstrates that application of the burden to the person... is in furtherance of a compelling governmental interest." 21 RFRA also specifies that the burden shifting encompasses both the burden of going forward and the burden of persuasion, ${ }^{22}$ and the Supreme Court has clarified that the government bears this evidentiary burden even when the issue is raised in the context of a motion for preliminary relief. ${ }^{23}$ That is, as to both prongs, the burden at the preliminary relief stage tracks the evidentiary burden at trial, and, thus, a challenger who has proved a prima facie case "must be deemed likely to prevail" unless the government can make its required showing. ${ }^{24}$

In $O$ Centro, the Court explained that the text of the RFRA makes clear that the burden of proof cannot be satisfied by merely pointing to broadly formulated interests. ${ }^{25}$ Rather, the RFRA requires the government to demonstrate that applying the law (the burden) to the person in fact furthers the compelling interest. ${ }^{26}$ In $O$ Centro, a small religious sect, UDV, challenged

19. See Brief for Breast Cancer Prevention Institute, et al. as Amici Curiae Supporting Appellants, Conestoga Wood Specialties Corp. v. Sebelius, 917 F. Supp. 2d 394 (E.D. Penn. 2013) (denying motion for preliminary injunction) (Nos. 13-354, 13-356), 2014 WL 334445.

20. See 42 U.S.C. $\$ 2000 b b-1(b)(1)-(2)$.

21. See id. $\$ 2000 \mathrm{bb}-1(\mathrm{~b})$.

22. See id. § $2000 \mathrm{bb}-2(3)$.

23. See Gonzales v. O Centro Espirita Beneficente Uniao Do Vegetal, 546 U.S. 418, 428-430 (U.S. 2006) [hereinafter O Centro] (relying on Ashcroft v. American Civil Liberties Union, 542 U.S. 656 (2004), and rejecting the government's argument that, because a challenger seeking preliminary relief bears the burden of showing likelihood of success on the merits, the challenger at the preliminary stage should bear the burden of disproving the asserted compelling interests).

24. O Centro 546 U.S. at 429.

25. Id. at 431 .

26. Id. 
the government's decision pursuant to the federal Controlled Substances Act (the "CSA") to bar the sect's use of hoasca for its communion services. ${ }^{27}$ Hoasca is a sacramental tea made, in part, from a native plant containing a hallucinogen (DMT) listed in Schedule I of the CSA. ${ }^{28}$ United States Customs inspectors had seized a shipment of hoasca and threatened UDV with prosecution. ${ }^{29}$ UDV sought a declaratory judgment and injunctive relief, arguing that applying the CSA to UDV's sacramental use of hoasca violated the RFRA. ${ }^{30}$ The government conceded that application of CSA would substantially burden a sincere exercise of religion by UDV, but had several arguments for why enforcement did not violate the RFRA. ${ }^{31}$ The Court's negative response to the government's arguments sheds substantial light on what is required in order for the federal government to justify a law that substantially burdens the free exercise of religion.

On appeal, the government presented an argument grounded in the general interest of uniform and across-the-board enforcement of the CSA. The government argued that the CSA creates a "closed" regulatory system that prohibits all use of controlled substances except as authorized by the CSA and, thus, the fact that the hallucinogen in hoasca, DMT, is listed in Schedule I of the CSA precluded any consideration of individualized exceptions under RFRA. ${ }^{32}$ One aspect of this argument was that drugs listed in Schedule I are those with "high potential for abuse" and "no currently accepted medical use," and which cannot be used safely even under medical supervision. ${ }^{33}$ For this reason, a compelling interest existed which would admit no exceptions. ${ }^{34}$ As such, the government argued that the particulars of UDV's use or of the impact of exemptions were not relevant because the need to enforce CSA itself serves as a compelling purpose. ${ }^{35}$

The Court in $O$ Centro noted that the RFRA expressly adopted the compelling interest test as set forth in two important free exercise cases, Sherbert v. Verner and Wisconsin v. Yoder. ${ }^{36}$ In those cases, the Court "looked beyond broadly formulated interests justifying the general applicability of govern-

27. $I d$.

28. Id. at 425 (explaining that hoasca is made from two plants native to the Amazon region, one of which contains dimethyltryptamine ("DMT")). The Controlled Substances Act, 84 Stat. 1242, codified as amended in 21 U.S.C. § 801 et seq., regulates the importation, manufacture, distribution, and use of psychotropic substances. The CSA classifies substances into five schedules based on several factors relating to dangerousness. $I d$. Substances listed in Schedule I are the most dangerous, and subject to the most comprehensive restrictions.

29. O Centro, 546 U.S. at 425.

30. Id. at 425-26.

31. Id. at 426 .

32. Id. at 430 .

33. Id. at 430 (quoting 21 U.S.C. § 812(b)(1)).

34. Id.

35. O Centro, 546 U.S. at 430.

36. Id. at 430-31 (quoting 42 U.S.C. § 2000bb(b)(1)) (citing Sherbert v. Verner, 374 U.S. 398 (1963) \& Wisconsin v. Yoder, 406 U.S. 205 (1972)). 
ment mandates and scrutinized the asserted harm of granting specific exemptions to particular religious claimants." 37 In Yoder, the state had asserted in support of a compulsory school attendance law an interest in ensuring the education of children. The Court recognized the validity of that interest generally, but held that the judicial role was to "searchingly examine" whether an exemption for Amish children would impede that interest, and also held that the state must show "with more particularity how its admittedly strong interest ... would be adversely affected" by an exemption for Amish children. ${ }^{38}$ In Sherbert, the Court upheld a religious exemption from a state law denying unemployment benefits to those who would not work on Saturdays, but, again, the exemption was deemed necessary as a matter of free exercise because the state could not show that, in the context of that particular challenger, the state interest in spurring productivity would be impaired. ${ }^{39}$ In light of the particularized nature of the compelling interest analysis, the Court in O Centro held that the government's "mere invocation" of the general characteristics of Schedule I substances and the purpose of the CSA could not carry the day: "Congress" determination that DMT should be listed under Schedule I simply does not provide a categorical answer that relieves the Government of the obligation to shoulder its burden under RFRA." 40

The Court bolstered its conclusion by pointing to other factors. First, the Court noted that the CSA itself authorizes the Attorney General to waive certain requirements if consistent with public health and safety. ${ }^{41}$ Second, the Court emphasized the existence of a long-standing regulatory exemption for religious use of another Schedule I substance, namely, use of peyote by the Native American Church. To the Court, the peyote exemption that permitted hundreds of thousands of Native Americans to use a Schedule I substance for religious purposes severely undercut the argument that Schedule I listing could preclude similar exemptions. ${ }^{42}$ Quoting from another free exercise case, the Court said: "a law cannot be regarded as protecting an interest 'of the highest order' ... when it leaves appreciable damage to that supposedly vital interest unprohibited." 43 To the Court, the peyote exemption also undercut the related argument that the CSA operates as a closed system and that uniformity is integral to its effectiveness. ${ }^{44}$

$O$ Centro thus makes clear that, as to the government's showing under the RFRA, it is not sufficient to identify a compelling interest that generally is

37. Id. at 431.

38. Id. (quoting from Yoder, 405 U.S. at 213, 221, 236).

39. Id. (quoting from Sherbert, 374 U.S. at 410 ).

40. Id. at 432 .

41. O Centro, 546 U.S. at 432-33 (citing 21 U.S.C. $\$ 822(d)$ ) (noting that the potential for exemptions indicates that congressional findings with respect to Schedule I substances should not carry determinative weight for RFRA purposes).

42. Id. at 433 .

43. Id. (quoting Church of Lukumi Babalu Aye, Inc. v. Hialeah, 508 U.S. 520, 547 (1993), quoting Florida Star v. B.J. F., 491 U.S. 524 (1989)).

44. Id. at $434-35$. 
implicated by the challenged federal law. The RFRA requires the government to demonstrate that applying the law (the burden) to the person in fact furthers the compelling interest and, in O Centro, the particularized showing was precluded due to the existence of exemptions. As to both the interest in controlling very dangerous Schedule I substances and the interest in uniform enforcement of the CSA, the Court acknowledged that, as a general matter, these are important governmental interests and, of course, enforcement of CSA furthers those interests. ${ }^{45}$ But, nonetheless, the government still was required to produce evidence showing that granting the particular request for accommodation would in fact significantly impair the interest at stake. As the Court explained, the government "can demonstrate a compelling interest in uniform application of a particular program by offering evidence that granting the requested religious accommodations would seriously compromise its ability to administer the program." 46 Conversely, however, a failure to produce evidence showing adverse consequences flowing from granting a particular request for an exemption will not justify a substantial infringement of religious liberty. ${ }^{47}$

This type of particularized showing will be required as to the contraceptive mandate, but, in addition, the context of the contraceptive mandate presents an additional issue. In O Centro, no one disputed that the CSA furthered certain general compelling interests, for example, effective control of very dangerous substances through rigorous enforcement of CSA. ${ }^{48}$ In contrast, as to the contraceptive mandate, objectors have repeatedly disputed that the law furthers the compelling interest asserted, namely, that contraceptives are preventive health care services necessary to promote women's health. ${ }^{49}$ As

45. The Court similarly recognized a general interest in meeting obligations under a U.N. treaty on psychotropic substances that covered hoasca. Id. at 437-38 (discussing the interest in complying with the 1971 United Nations Convention on Psychotropic Substances).

46. Id. at 435-37 (explaining that cases in which an interest in uniformity sufficed to deny accommodation, courts had scrutinized the asserted need and explained why the requests could not be accommodated).

47. Id. at 438-39 (rejecting the government's assertion of a general interest in meeting obligations under the U.N. treaty because "the government simply submitted affidavits by State Department officials attesting to the general importance of honoring international obligations").

48. As to both the interest in controlling very dangerous Schedule I substances and the interest in uniform enforcement of the CSA, the Court acknowledged that, as a general matter, these are important governmental interests. O Centro, 546 U.S., at 432 . The Court similarly recognized a general interest in meeting obligations under a U.N. treaty on psychotropic substances that covered hoasca. Id. at 437-38 (discussing the interest in complying with the 1971 United Nations Convention on Psychotropic Substances).

49. For example, comments submitted August 31, 2011, by the Office of the General Counsel for the USCCB included the argument that contraceptives and sterilization are not health services and do not prevent illness or disease. See Letter from Office of the General Counsel, U.S. Conference of Catholic Bishops, to Center, for Medicare \& Medicaid Servs., Dep't of Health and Human Servs. (Aug. 31, 2011) available at, http://www.usccb.org/about/general-counsel/rulemaking/upload/comments-to-hhs-on-preventive-services-2011-08.pdf (the August 2011 comments included, in an appendix, the more in-depth argument as to the issue submitted by the conference in September 2010). Similar health-based arguments were submitted by the Catholic Medical Association ("CMA"). Letter from Maricela P. Moffitt, President of the Catholic Medical Assocation, to Center for Medicare \& 
to this aspect of the government's burden under the RFRA, the trial court's decision in $O$ Centro is instructive. The government had pointed to two other compelling interests: protecting the health and safety of the public (and UDV members in particular), and preventing the diversion of hoasca from the church to recreational users. ${ }^{50}$ UDV disputed that enforcement of CSA would further these interests. Given the dispute, the district court held an evidentiary hearing and found the evidence "virtually balanced." 51 The government presented evidence relating to the potential adverse health effects related to hoasca (psychotic reactions, cardiac irregularities, adverse drug interactions), but UDV countered with evidence that minimized the likelihood of health risks and by citing studies documenting the safety of its sacramental use. ${ }^{52}$ As to diversion, the government pointed to a general rise in the illicit use of hallucinogens, and to an interest in DMT in particular and to hoasca itself.UDV countered with evidence of the thinness of any market for hoasca, the small quantity imported by the church, and the absence of any diversion problem in the past. ${ }^{53}$ Given the balanced nature of the evidence, the court found that the government had not satisfied its burden and issued a preliminary injunction prohibiting enforcement of CSA as to UDV's importation and use of hoasca. ${ }^{54}$

Several aspects of the $O$ Centro decision are instructive: the Supreme Court's focus on properly identifying the compelling interest at stake and on the impact of existing exemptions, and the trial court's focus on evidence showing that application of the law to the challenger will genuinely further the relevant compelling interest. ${ }^{55}$ In many cases, resolution of the RFRA analysis will hinge on the strength of the government's evidentiary basis for its claims. Given the disputed issues in the controversy surrounding the contraceptive mandate, all of these aspects of a RFRA analysis will be at play.

Medicaid Servs., Dep't of Health and Human Servs. (June 19, 2012) available at, http://www.cathmed.org/issues_resources/publications/press_releases/cma_provides_comments_on_hhs_proposed_accommodation/.

50. O Centro, 546 U.S. at 426 . As to both the interest in controlling very dangerous Schedule I substances and the interest in uniform enforcement of the CSA, the Court acknowledged that, as a general matter, these are important governmental interests. Id. at 432. The Court similarly recognized a general interest in meeting obligations under a U.N. treaty on psychotropic substances that covered hoasca. Id. at 437-38 (discussing the interest in complying with the 1971 United Nations Convention on Psychotropic Substances).

51. Id. at 426-27 (the evidence as to health risks was "in equipoise," and as to diversion was "virtually balanced").

52. Id. at 426 .

53. Id.

54. Id. at 427 (the injunction allowed importation and sacramental use by UDV, but also imposed several restrictions on UDV).

55. Id. On appeal the government did argue that the balanced nature of the evidence should not mean that UDV had shown a likelihood of success on the merits. That is, the government argued that, because the issue was being addressed on a motion for preliminary relief, UDV had the burden of disproving the government's compelling interest. Id. at 428-430. But the Court rejected this argument. 


\section{THE LITIGATION}

In the lawsuits challenging the contraceptive mandate, the government has addressed the issues arising due to its RFRA burden of proof, but, at best, has presented a weak case. The government has argued that the mandate advances interests in public health and gender equality. ${ }^{56}$ Yet the Government also frames the argument in terms of a woman's constitutionally protected interest in controlling her procreation, which is a privacy interest more so than a health interest. ${ }^{57}$ All of these interests are, in general, important, and the Government has pointed to basic, general principles no one would seriously doubt:

That government can safeguard the public health through regulation of the health care or insurance markets.

That access to health care is promoted by insurance coverage and reducing or eliminating cost-sharing.

That it is important to remove barriers to economic advancement and political and social integration for women.

That ensuring equal access to goods, privileges, and advantages is important.

That access to preventive health care is important to women's health and advancement. ${ }^{58}$

Under the RFRA, however, questions arise as to what compelling interest is relevant, whether the contraceptive mandate serves that interest, and whether exempting employers with religious objections would seriously impair the mandate's ability to advance that interest.

\section{A. Will Additional Religious Exemptions Impair the Compelling Interest?}

In light of the $O$ Centro decision, the plaintiffs and courts in the lawsuits challenging the contraceptive mandate have tended to focus primarily on the impact of the numerous exemptions HHS has otherwise provided, and the failure of the government to address the question of the impact of additional religious exemptions with particularity. For example, the opponents' briefs emphasize that the government has itself voluntarily elected to exempt tens of millions of employees and participants, both as to grandfathered plans and via the existing exemption for religious employers. ${ }^{59}$ A majority of the Tenth

56. See Brief for the Appellees at 35-36, Conestoga Wood Specialties Corp. v. Sebelius, 917 F. Supp.2d 394 (E.D. Penn., 2013) (No. 12-6744) (hereinafter Gov't Brief, Conestoga Woods); see also Brief for the Appellees at 35-36, Grote Industries v. Sebelius, 914 F. Supp.2d 943 (S.D. Ind., 2012) (No. 131077) (hereinafter Gov't Brief, Grote Industries). In the Hobby Lobby litigation, the Government's argument on these issues is less developed. See Brief for the Appellees at 16-17, Hobby Lobby Stores. v. Sebelius, 870 F.Supp.2d 1278 (W.D. Okla., 2012) (No. 12-1000) (hereinafter Gov't Brief, Hobby Lobby).

57. Gov't Brief, Conestoga Woods, supra note 56, at 34; see also Government Brief, Grote Industries, supra note 56 , at 34 .

58. Gov't Brief, Conestoga Woods, supra note 56, at 35-37; Government Brief, Grote Industries, supra note 56 , at $35-37$.

59. See Reply Brief for Appellant at 14-15, Grote Industries v. Sebelius, 914 F. Supp.2d 943 (S.D. 
Circuit Court of Appeals in Hobby Lobby Stores, Inc. v. Sebelius, found this argument to be determinative. ${ }^{60}$ It noted that the Government has articulated only "broadly formulated interests" in "public health" and "gender equity" and offered "almost no justification for not granting the specific exemptions to particular religious claimants." 61 In particular, the court agreed that the Government's case was significantly compromised by the existing exemptions: "If the peyote exemption in O Centro, which applied to "hundreds of thousands of Native Americans' was enough to undermine the Government's compelling interest argument in that case, we conclude the exemptions for millions of individuals here must dictate a similar result." 62

However, additional analysis is warranted. In O Centro, the asserted interest was the need for "uniformity" and the "closed system" of the CSA. In the face of that asserted interest, the existence of numerous exemptions would seriously undercut the compelling nature of the interest. The same result does not necessarily follow as to an interest in public health or gender equality. Where the goal is to reach as many people as possible, the existence of exemptions - even numerous exemptions - does not mean the government does not still legitimately have a strong interest in avoiding additional exemptions. In this light, the plaintiffs' argument is not as unassailable as the majority in Hobby Lobby suggested. Further, the government has argued that the plaintiffs have mischaracterized the extent of existing exemptions in the law. Specifically, many of the exemptions stem from the ACA's grandfathering provisions which, in the government's estimate, will result in only shortterm exemptions: according to the government, a majority of plans will lose grandfathered status by $2013 .{ }^{63}$

But that argument does not explain away all the exemptions, nor address the particular requests at issue. On this point, the government has argued only that the requested exemptions would undermine Congress's objectives because, "whereas Congress sought to increase access to women's preventive health services ..., plaintiffs seek to exclude contraceptive coverage entirely from the [employee health] plan." 64 This showing remains insufficient under $O$ Centro. O Centro would require the government to quantify its argument

Ind., 2012) (No.13-1077); see also Brief of Archdiocese of Oklahoma City at 24-25, Hobby Lobby Stores v. Sebelius, 870 F.Supp.2d 1278 (W.D. Okla., 2012) (No. 12-6294).

60. Hobby Lobby, 723 F.3d at 1143-44.

61. Id.

62. Id. at 1144; see also Tyndale House Publishers, Inc. v. Sebelius, 904 F. Supp. 2d 106, 128-29 (D.D.C. 2012) (noting "because the government has not 'assess[ed] the particulars of the [plaintiffs']' objections, nor 'weigh[ed] the impact of an exemption for [their] specific' objection, O Centro [cite omitted], and considering the myriad of exemptions to the contraceptive mandate already granted by the government [(which excludes 191 million employees affected by the grandfathered plans alone)], the defendants have not shown a compelling interest in requiring the plaintiffs to provide the specific contraceptives to which they object").

63. See Gov't Brief, Conestoga Woods, supra note 56, at 38-39; Gov't Brief, Grote Industries, supra note 56, at 38-39; Gov't Brief, Hobby Lobby, supra note 56, at 39 (all citing 75 Fed. Reg. 34,538, 34,552 (June 17, 2010)).

64. See Gov't Brief, Conestoga Woods, supra note 56, at 37; Gov't Brief, Grote Industries, supra note 56 , at 37 . 
in a two-fold manner. First, Yoder and Sherbert require a showing tailored to the particular challenger. In this regard, it is relevant that one challenger has pointed out that the Government has failed to provide evidence of a "pandemic of unwanted births" which might cause serious health consequences for employees at businesses similar to those challenging the mandate entities. ${ }^{65}$ Second, the Government would need to quantify in some manner how a narrow exemption for one of the many services designated as "women's preventive services" would undermine the general interests-especially given the relatively small number of employers who are seeking religious exemptions.

For reasons that become clear in the analysis presented in the remainder of this article, both of these showings may be difficult for the government to make. This is because the evidence suggests that additional religious exemptions to the contraceptive mandate for working women will not significantly impact women's health generally, and, further, does not suggest that exemptions as to contraceptive coverage will significantly undermine Congress's purpose in enacting the general women's preventive services mandate. Rather, the evidence supports numerous propositions that undermine the government's case, including the government's overarching assertion that contraceptive services are essential for women's health.

\section{B. Will the Mandate Further the Compelling Interest?}

The government claims the contraceptive mandate advances the general interests in public health, gender equality, and women's right to control procreation. As noted, no one would dispute that these are, generally, important governmental interests. However, under the RFRA, the issue is whether the evidence demonstrates that the contraceptive mandate serves these interests. Further, an important threshold question is whether the government has properly identified interests that are relevant in this particular RFRA claim. That is, what interest did Congress intend to be furthered by the women's preventive services mandate?

\section{1) Properly Identifying the Relevant Interest}

The specific statutory language in the ACA which led to HHS's promulgation of the women's preventive services mandate directs health insurance issuers and group health plans (except grandfathered health plans) to offer policies that cover, without cost sharing, inter alia:

Evidence-based items or services that have in effect a rating of " $A$ " or " $B$ " in the current recommendations of the United States Preventive Services Task Force (USPSTF) ...

$\ldots$ and,

65. See, e.g., Gov't Brief, Grote Industries, supra note 56, at 33-34. 
(4) with respect to women, such additional preventive care and screenings not described in paragraph (1) as provided for in comprehensive guidelines supported by the Health Resources and Services Administration for purposes of this paragraph. 66

The challenged contraceptive coverage mandate is but a subset of the regulatory scheme devised to give effect to the directive in subsection (4) that employer provided health plans should cover preventive care and services for women. It is thus appropriate to examine the legislative history surrounding that general directive. Subsection (4) became part of the ACA as a result of a floor amendment to the final Senate bill offered by Barbara Mikulski, Senator from Maryland. ${ }^{67}$ In introducing the amendment, Mikulski praised the Senate bill, but explained her view that Congress should do more to enhance and improve women's health. ${ }^{68}$ In particular, Mikulski pointed to the "top killers" of women - breast cancer, cervical cancer, colorectal cancer, ovarian cancer, lung cancer, heart and vascular disease, and diabetes and the screenings proven to detect these diseases early, and explained: " $[\mathrm{M}] \mathrm{y}$ amendment ... guarantees access to those critical preventive services for women to combat their No. 1 killers. We will provide these services at minimal cost." 69 Later in the debate, in response to a query regarding the potential to interpret the amendment as allowing abortion to be considered part of women's preventive services, Mikulski stated: “Abortion has never been defined as a preventive service. This amendment is strictly concerned with ensuring that women get the kind of preventive screenings and treatments they may need to prevent diseases particular to women such as breast cancer and cervical cancer." 70 Other Senators echoed the importance of attention to women's health, noting that the amendment would ensure that,

66. Section 1001 of the ACA amended the Public Health Service Act by inserting a new section 2713. Patient Protection and Affordable Care Act, Pub. L. No. 111-148, 124 Stat. 119 (2010). The amendment also clarifies that the USPSTF guidelines regarding breast cancer screening, mammography, and prevention shall be considered the most current other than those issued on or around November 2009. See id. § 2713(a)(5).

67. Mikulski proposed the amendment on November 30, 2009, during the floor debate of House Resolution 3590. See 155 CONG. REC. S11986-87 (daily ed. Nov. 30, 2009) (statement of Ms. Mikulski regarding amendments 2786 to 2791). House Resolution 3590, the final Senate bill, was introduced in the Senate on November 19, 2009. H.R. Res. 3590, 111th Cong. (2009) (enacted). It passed in the Senate on December 24, 2009. Id. In March 2010 the House passed the Senate bill, along with a reconciliation bill that went back to the Senate for consideration. Id. It was this bill that ultimately was signed by the president and became law. See Patient Protection and Affordable Care Act, Pub. L. No. 111-148, 124 Stat. 119 (2010), amended by Health Care and Education Reconciliation Act of 2010, Pub. L. No. 111-152, 124 Stat. 1029. The reconciliation process is intended to be used to pass budgetary changes to existing laws. It is considered privileged in the Senate, meaning it is not subject to debate and therefore not subject to filibuster. See Martin B. Gold, SENATE PROCEDURE AND PRACTICE 153-55 (2d ed. 2008).

68. See 155 CONG. REC. S11987 (daily ed. Nov. 30, 2009).

69. Id. at $\mathrm{S} 11987-88$.

70. See id. at $\mathbf{S 1 2 2 7 4}$ (addressing a concern raised by Mr. Casey). Mr. Brownback, Senator from Kansas asked Mikulski to include express language clarifying that the ACA would not be construed as authorizing HHS or any other agency from classifying abortion services as "preventive care" or "preventive services." Id. at 12274-75. 
when deciding which preventive services all health plans would be required to include, there would be a distinct focus on the needs of women. The amendment would help ensure that women-whose role is essential to a family's well-being - would not forego essential preventive health care during hard economic times. ${ }^{71}$

The floor debate, then, focused on the importance of identifying preventive services genuinely needed to improve women's health. The clear bulk of the debate centered on preventive services crucial for early detection of life threatening diseases particular to women such as breast cancer and cervical cancer. Contraceptive services are fundamentally distinct from these preventive services. As discussed infra, sterilization and most contraceptive methods disrupt and distort the normal operation of a healthy reproductive system and, at the same time, subject women to serious health risks. ${ }^{72}$ The question thus arises whether any legislative support exists for inclusion of contraception and sterilization services in the women's preventive services mandate.

Notably, during the course of the debate contraception was never mentioned at all. Mikulski noted, however, that if this amendment passes, "women will have access to the same preventive health services as the women in Congress have."73 Because the health plan available to federal employees covers contraceptives, her statement technically constitutes a reference-albeit a hidden reference-to contraceptive services. Additionally, a few commentators made passing references to family planning. For example, Senator Murray noted that "[w]omen will have improved access to wellwomen visits - important for all women: family planning services; mammograms, which we have all talked about so many times, to make sure they maintain their health." ${ }^{74}$ Similarly, Senator Franken noted that, under the amendment, the Health Resources and Services Administration would be able to include services beyond those recommended by the USPSTF: "other important services ... such as the well woman visit, prenatal care, and family planning. These preventive services will truly improve woman's health."75 Effective family planning can be achieved without contraception, but, the phrase very often is used to refer to access to contraceptive items and services. ${ }^{76}$ Thus, although not clear in the text of the amendment or in the clear

71. See id. at S12274 (statement by Ms. Murray). Given the emphasis on promoting women's health, the amendment elicited strong emotional support: Mr. Baucus, Senator from Montana, praised the efforts of Mikulski because "I have a mom. I have sisters. I have women in my family, and I very much care." Id. at S11988. Similarly, Mr. Franken, Senator from Minnesota, stated: "[W]e need to include this amendment because I want to be able to look my wife in the eye, I want to be able to look my daughter in the eye - my son, too - and my future grandchildren in the eye and say we did everything we could in this bill to improve women's health." Id. at S12272.

72. See infra notes 157-78, 202-21 and accompanying text.

73. 155 CONG. REC. S11987 (daily ed. Nov. 30, 2009).

74. Id. at $\mathrm{S} 12274$.

75. Id. at $\mathrm{S} 12271$ (statement of Sen. Franken).

76. Indeed, in the medical and public health professions, contraception is commonly referred to as "family planning." See Brief for Standridge, et al. as Amicus Curiae of the American College of 
bulk of the floor debate, a few statements show that some lawmakers envisioned the amendment would encompass coverage for contraceptive services. ${ }^{77}$ Importantly, however, the statements were made within the context of - and thus are delimited by - the strong, overarching, and expressly stated concern for promoting women's health. ${ }^{78}$

In light of the relevant legislative history, the Government has framed its case too broadly. The Government certainly has a strong interest, generally, in public health, gender equality, and women's privacy rights related to procreation. However, Congress's purpose in enacting the women's preventive services directive was not to foster constitutionally protected privacy interests or the general interest in gender equity. Rather, Congress intended to foster access to preventive health care services crucial for early detection of life threatening diseases, and especially preventive screenings and treatments women may need to prevent diseases particular to women such as breast cancer and cervical cancer. The relevant compelling interest at stake can thus be framed more accurately as the interest in providing coverage for preventive health care services that will help women maintain good health by identifying or treating serious diseases; or, stated more succinctly, the interest in providing coverage for preventive services needed to protect women's health. In the litigation, the issue is whether the contraceptive mandate-as applied to the persons requesting exemptions - furthers this interest. Under RFRA the Government must demonstrate that it does and, in doing so, must produce evidence that satisfies the burden of production and the burden of persuasion.

Obstetricians and Gynecologists Supporting Plaintiffs-Appellees, at n. 5, Standridge v. Union Pacific R.R., 479 F. 3d 936 (8th Cir. 2006).

77. Notably, a key and self-interested proponent of a contraceptive-based approach to family planning and insurance coverage of contraceptives makes the exaggerated claim that the floor debate "made clear that the Mikulski amendment was intended by its supports to include contraceptive counseling, services and supplies, as well as annual well-woman gynecologic exams and other key services." See Adam Sonfield, The Case for Insurance Coverage of Contraceptive Services and Supplied Without Cost Sharing, 15 GUTTMACHER INST. POLICY REV. 1, 7 (2011). The bias of "articles" published under the umbrella of the Guttmacher Institute is often glaringly apparent. For example, this Sonfield article-which was relied on by HHS in the agency's explanation of the contraceptive mandatestates (i) that "contraceptive services" have long been recognized by government bodies as a vital and effective component of preventive and public health care and (ii) that "cost can be a daunting barrier to effective contraceptive use." Id. at 7. Yet, study of other Guttmacher publications clarifies (i) that government bodies recognize the importance of "family planning" - not contraceptives (see Adam Sonfield, Contraception: An Integral Component of Preventive Care for Women, 13 GUTTMACHER INST. POLICY REV. 2, at 4-5 (2010) and (ii) that only 1 in 10 women who had experienced a gap in contraceptive use cited difficulty accessing the contraceptive as being the cause for the gap. See Guttmacher Institute, In Brief: Improving Contraceptive Use in the United States, at 6 (2008).

78. Some members of Congress also were concerned with purported discrimination against women in health care and health insurance coverage. See, e.g., 155 CONG. REC., S11,987 (daily ed. Nov. 30, 2009) (statement of Sen. Mikulski) (noting that the bill - without the Mikulski amendment "will end the punitive practices of insurance companies, particularly in the area of gender, age discrimination, and preexisting conditions."). But a fair reading of the text and the legislative history relating to the amendment as to women's preventive services points towards an overarching congressional concern for promoting women's health. 
2) The Brief Amici Curiae

In the litigation, the government has produced evidence relating to an interest in coverage for preventive services needed to protect women's health, but here too the Government's case suffers from weaknesses. In reviewing the government's briefs, it is clear the Government relies predominantly on the 2011 report that HHS relied on in the rulemaking process, the report wherein the Institute of Medicine ("IOM") recommended in a 2011 report that women's preventive services include contraception and sterilization services. ${ }^{79}$ For example, the Government notes that IOM relied on a study showing that eliminating cost-sharing for contraceptives made it more likely that women would use "more effective long-acting contraceptive methods;" 80 and that the IOM report states that access to contraceptives "is a crucial public health protection because unintended pregnancy can have major negative health consequences for both the woman and the developing fetus." 81

In this light, it is important that opposing briefs have raised serious questions about the probative value of the 2011 IOM Report. Some challengers have discounted the report in a conclusory manner, arguing that reliance on the report is insufficient because it makes a case only for a generic health benefit from contraception; and research supposedly supporting the case is based on correlation, not evidence of causation, and also suffers from significant admitted flaws in methodology. ${ }^{82}$ However, a more pervasive and quantitative attack is presented in a brief amicus curiae filed by, inter alia, the Breast Cancer Prevention Institute ("BCPI"), which provides more detail as to gaps and methodological flaws of the IOM report. ${ }^{83}$

The crux of the government's argument that the mandate promotes the interest in maintaining women's health hinges on the proposition that access to contraceptives without cost sharing will cause an increase in use of contraceptives, especially use of longer-lasting formulations, and a decrease in unintended pregnancies. The BCPI brief emphasizes that studies cited in the 2011 IOM Report do not prove these consequences are likely to flow from the

79. See Institute of Medicine, Clinical Preventive Services for Women, Closing the Gaps (Washington, D.C.: National Academic Press, 2011) (hereinafter Closing the Gaps); see also infra Part III(B) for a critical analysis of the 2011 IOM Report.

80. See Gov't Brief, Conestoga Woods, supra note 56, at 35; see also Gov't Brief, Grote Industries, supra note 56 , at 35 .

81. See Gov't Brief, Conestoga Woods, supra note 56, at 36; see also Gov't Brief, Grote Industries, supra note 56, at 36. Other arguments are more conclusory: for example, the government argues that "Congress found" that women spend " 68 percent more in out-of-pocket health care costs than men," that this burden creates barriers that prevent women from achieving health and well-being, and that the contraceptive mandate will help equalize access to preventive health care. See Gov't Brief, Conestoga Woods, supra note 56, at 37; see also Gov't Brief, Grote Industries, supra note 56, at 37.

82. See, e.g., Brief for Appellants, Grote Industries, supra note 56, at 33-34.

83. See Brief Amici Curiae of Breast Cancer Prevention Institute, Polycarp Research Institute, and Coalition on Abortion/Breast Cancer Supporting Appellants, at 6, Conestoga Wood Specialties Corp. v. Sebelius, 917 F. Supp.2d 394 (E.D. Penn.2013) (No. 12-6744) [hereinafter BCPI brief] (denying motion for preliminary injunction). 
mandate. For example, the brief explains that studies cited by IOM show that 89 percent of women avoiding pregnancy are already using contraception, and among the other 11 percent lack of access is not a statistically significant reason why contraception is not used. ${ }^{84}$ The brief also points out that the 2011 IOM Report ignored statistical evidence showing that decades of governmental promotion of low or no-cost contraception and emergency contraception had failed to reduce unintended pregnancies, and, indeed, the fact that the current rate of unintended pregnancy reflects a 40 percent increase since 1972 (despite "multiple programs and policies operating on the same premise as the HHS mandate"). ${ }^{85}$ Moreover, BCPI notes that a key source relied on by IOM (the 1995 IOM publication analyzed infra) acknowledges methodological difficulties in defining and identifying pregnancies that present health concerns ${ }^{86}$ and that the purported link between "unintended pregnancy" and negative health outcomes is not one of causation, but, rather, one of association only. ${ }^{87}$ BCPI notes:

This makes sense, since the intendedness or unintendedness of a pregnancy cannot itself physiologically change its health effect. Thus, [for example,] a delay in seeking prenatal care for an unintended pregnancy may be "no longer statistically significant" for women who are not already disposed to delay or who have a "support network" - as do the Plaintiffs' insured employees, as well as the employees' spouses and dependents. ${ }^{88}$

Numerous other gaps or flaws were cited in support of BCPI's overarching view that "the Government's argument is based on a chain of presumed causes and effects, and the evidence supporting each link is attenuated, ambiguous, disputed, or non-existent." 89

Moreover, the BCPI brief shows that the Government's case falls short for another key reason. The relevant compelling interest is health coverage for services needed to protect women's health. Yet, the BCPI brief emphasizes

84. See BCPI Brief, supra note 83 , at 8 (citing Jo Jones et al., Use of Contraception in the United States (June 2010), http:/ / www.guttmacher.org/pubs/fb_contr_use.html (last visited September 20, 2012).

85. Id. at 9-11.

86. Id. at 12 (citing SARAH S. BROWN \& LEON EISENBERG FOR THE INSTITUTE OF MEDicine, CoMMITTEE ON UNINTENED PREGNANCY, THE BEST INTENTIONS (1995)).

87. Id. at 12-17 (citing Jessica D. Gipson et al., The Effects of Unintended Pregnancy on Infant, Child, and Parental Health: A Review of the Literature, 39 STUD. FAM. PLAN. 18 (2008)). BCPI points out evidentiary deficiencies as to most risks the IOM points to in making the recommendation to include contraceptives in the mandate: for example, behavioral risks affecting the health of mothers (smoking, drinking, depression, domestic violence), noting the paucity of studies and the lack of any proof of causation; infant low birth weight, noting inconsistent study results, low birth rates even with lengthy pregnancy intervals, and lack of any research into long-term health effects; and the special needs of some women to postpone pregnancy, noting that the conditions pointed to by the government are conditions that magnify many serious health risks associated with hormonal contraceptives.

88. Id. at 12 (citing BROWN, SUPRA NOTE 82).

89. Id at 6 . The BCPI brief similarly questions the logic of the Government's claim that the mandate advances gender equality. For a summary of the BCPI argument relating to the equality claim, see infra note 90 . 
that the Government in the rulemaking process and the 2011 IOM Report totally ignored the large body of peer-reviewed scientific evidence that demonstrates significantly increased serious health risks associated with contraceptive drugs. ${ }^{90}$ This point is explored in greater depth infra, but at the outset it is noteworthy that BCPI cites studies showing, among other risks, that contraceptive drugs are known to be associated with the following:

higher risk of heart attack (doubling the risk for those with no other risk factors, and increasing the risk up to 23 times for those with risk factors); $; 1$

higher risk of stroke (tripling the risk for those with no other risk factors, and increasing it more for those with risk factors) $;{ }^{92}$

higher risk of breast cancer (a 44 percent increased risk in women who took oral contraceptives before having a child, ${ }^{93}$ and a 320 percent increased risk of triple-negative breast cancer); $; 4$

higher risk of cervical cancer (a three to fourfold increased risk); 95

higher risk of liver tumors or cancer; ${ }^{96}$ and

greater susceptibility to sexually transmitted diseases (for example, being twice as likely to be infected with genital human papillomavirus virus); 97 and

that the newer, longer-lasting contraceptives carry additional serious risks. ${ }^{98}$

Thus, as stated by BPCI, the services which the government is promoting via the mandate - longer and more consistent use of hormonal contraceptives - "fail the most important test of preventive medicine: they increase risk of disease instead of decreasing it." 99 As BPCI also aptly notes, if contraceptives do not genuinely promote women's health, it becomes illogical to argue

90. Id. at 18-21 ("The Government has failed to Show that the Mandate Furthers its Asserted Interest of Promoting Gender Equity"); Id. at 21-31 ("Because the Mandate Includes Hormonal Contraceptives that Significantly Increase Risks of Serious Disease, It Cannot Further a Compelling Interest in Promoting Women's Health Under RFRA, and It Is Arbitrary and Capricious Under the APA.").

91. Id. at 23-24 (citing Bea C. Tanis et al., Oral Contraceptives and the Risk of Myocardial Infraction, 345 NEW ENG. J. MED. 1787 (2001)).

92. Id. at 24 (citing Leslie A. Gillum, Ischemic Stroke Risk with Oral Contraceptives, 284 J. AM. MED Ass'N 72 (2000)).

93. Id. at 24 (citing Chris Kahlenborn et al., Oral Contraceptive Use as a Risk Factor for Premenopausal Breast Cancer: A Meta-Analysis, 81 MAYO ClinIC Proc. 1290 (2006)).

94. Id. at 25 (citing Jessica M. Dolle et al., Risk Factors for Triple Negative Breast Cancer in Women Under the Age of 45, 18 CANCER EPIDEMIOLOGY BIOMARKERS PREVENTION 1157 (2009)).

95. Id a at 25-26 (citing NATIONAL CANCER INSTITUTE: ORAL CONTRACEPTIVES AND CANCER RISK (March 21, 2012)).

96. Id.at 25 (citing NATIONAL CANCER INSTITUTE, supra note 95).

97. Id. at 26-27 (Citing Silvano de Franceschi et al., Genital Warts and Cervical Neoplasia: An Epidemiological Study, 48 BRIT. J. CANCER 621 (1983)); see also Brief Amici Curiae of Women Speak for Themselves, Bioethics Defense Fund, and Life Legal Defense Foundation in Support of Plaintiffs-Appellants at 7-11, O'Brien v. U.S. Dep't of Health and Human Servs., 894 F. Supp. 2d 1149 (2012) (No. 123357) [hereinafter WST Brief, O'Brien]; Brief Amici Curiae of Women Speak for Themselves in Support of Plaintiffs-Appellants and Reversal at 12-16, Belmont Abbey College v. Sebelius, 878 F. Supp. 2d 25 (2012) (No. 11-1989) [hereinafter WST Brief, Belmont Abbey].

98. Id, at 27-31; see also, e.g. MIRIAM ZIEMAN, ET AL., MANAGING CONTRACEPTION 37 (Ardentmedia, Inc. eds., 10th ed. 2010); WST Brief, O'Brien, at 11-15; WST Brief, Belmont Abbey, at 16-21.

99. BCPI Brief, supra note 79, at 22. The majority opinion in Gilardi took note of BCPI's premise, 
that they advance any concern Congress had in relieving women of any existing inequitable financial burden they face in maintaining their health. ${ }^{100}$

Those opposing the contraceptive mandate via litigation have thus raised serious questions regarding the sufficiency of the evidence underlying the government's claim that the mandate furthers the relevant compelling governmental interest. ${ }^{101}$ Significant omissions and methodological shortcomings of the 2011 IOM Report - if they exist - would seriously undermine the government's case. As in $O$ Centro at the trial court level, resolution of this issue may well require an evidentiary hearing, which in-turn would hinge on a battle of the experts: experts who could provide information about the reliability of the research relied on by the government and the reliability of the conclusions asserted by the government.

Yet, an evidentiary hearing perhaps could be avoided - or at least simplified - if significant shortcomings are obvious or discernible as matter of common sense and logic. ${ }^{102}$ The remainder of this article scrutinizes the evidence from this perspective. Further, the scrutiny extends beyond the evidence relied on by the government in the litigation - the 2011 IOM Report - to the fuller range of evidence relevant to the government's case, namely, to key evidence the Institute of Medicine relied on in issuing the 2011 IOM Report: conclusions of the American Congress of Obstetricians and Gynecologists and a highly influential 1995 IOM publication on unintended pregnancy. Scrutiny of the evidence reveals shortcomings and flaws of such a magnitude that it becomes reasonable to assert that ideology rather than evidence was

noting that the scientific evidence may actually undermine the Government's cause. See Gilardi v. U.S. Dep't of Health and Human Servs., 733 F.3d 1208, 1221 (D.C. Cir. 2013) (citing BCPI brief, supra note 79) (acknowledging that the evidence relevant to whether contraceptive drugs may actually avert negative health outcomes for women is debatable, and pointing, in particular, to the fact that "the World Health Organization classifies certain oral contraceptives as carcinogens, marked by an increased risk for breast, cervical, and liver cancers.")

100. Id. at 18-19. The BCPI brief also presents several other reasons why it is reasonable to question the logic of and evidentiary support for the Government's claim that the mandate advances gender equality. For example, BCPI points out the lack of any evidence for the proposition that women incur greater out-of-pocket expenses for preventive care, and especially for contraceptives. Id. For wives of male employees or female dependent children of employees, neither the Government nor the IOM have pointed to evidence showing that the expenses are not a shared household expense. Similarly, for covered female employees, the Government's case rests on an assumption that her outof-pocket health care expenses are borne by her alone. However, especially as to contraceptives, "the employee's need for contraceptives indicates some intimate relationship with a man ... The Government apparently assumes without proof that men-whether husbands, roommates, or in some other role-in intimate relationships with women do not contribute to the costs of whatever contraceptive method is used by the couple." Id. at 20-21.

101. Some judges have expressly noted that they are willing only to assume that the mandate may actually advance the generally asserted interest in woman's health or equality. See, e.g., Conestoga Woods Specialties Corp. v. Sec'y of the Dep't of Health and Human Servs., 724 F.3d 377, 412 (3d Cir. 2013) (Jordan, J., dissenting).

102. The Daubert factors used by federal courts in evaluating expert evidence allow, and indeed require, judges to scrutinize the evidence for signals that cast doubt on reliability; and those signals often are discernible as a matter of logic and/or common sense. See, e.g., Kumho Tire Co. v. Carmichael, 526 U.S. 137 (1999); Daubert v. Merrell Dow Pharm., Inc., 43 F.3d 1311 (9th Cir.), cert. denied, 516 U.S. 869 (1995). 
the driving force behind the mandate. In a RFRA claim, promoting a mere ideology will not satisfy the government's burden.

\section{SCRUTINY OF THE EVIDENCE}

The centrality of the 2011 IOM Report as the evidentiary support for the contraceptive mandate (and thus also the sources the report depends on) is clear from the rulemaking process leading to the mandate. Key points in the rulemaking process included Interim Final Rules issued in July 2010, Amended Interim Final Rules issued in August 2011, the Final Rule issued in February 2012, and the Final Rule issued in July 2013. ${ }^{103}$ Promulgation of the basic contours of the HHS preventive services mandate occurred in July 2010. ${ }^{104}$ However, the July 2010 Interim Final Regulations implemented the mandate using mere "parroting regulations." That is, the substance of the interim regulation merely restated the statutory text of section 1001 of the ACA, and thus the regulations provided very little insight into the content of women's preventive services. ${ }^{105}$ The preamble to these interim regulations explained that HHS planned to develop the "guidelines" and expected to issue them no later than August 1, 2011. ${ }^{106}$ HHS issued Amended Interim Final Regulations in August 2011. The key purpose of the amended interim regulations, however, was to incorporate into the regulations HHS's decision to use a very narrow version of a religious exemption; they also did not include guidance as to the content of women's preventive services. ${ }^{107}$

Rather, the content of preventive services to be included in the mandate came to light via a distinct process. In July 2011, information about the list of particular services that likely would be mandated became public. Specifically, on July 19, 2011, the IOM issued a report identifying the services IOM had decided should be covered under the ACA. ${ }^{108} \mathrm{HHS}$ promptly adopted the IOM recommendations on August 1, 2011, and HRSA put them into the

103. The key purpose of the August 2011 Amended Interim Final Regulations was to incorporate into the regulations HHS's decision to use a very narrow version of a religious exemption to address First Amendment concerns. See 76 Fed. Reg. 46621-46626 (Aug. 3, 2011). In February 2012, HHS issued the Final Rule, which finalized without change the narrow religious exemption. See 77 Fed. Reg. 8725-8730 (Feb. 15, 2012). The Final Rule, issued July 2, 2013, eliminated certain criteria, but retained the limitation that an exempt religious employer be a nonprofit organization related in some way to a religious organization. See 78 Fed. Reg. 39870, 39874 (July 2, 2013). See also USCCB, supra note 8.

104. See 75 Fed. Reg. 41726--41760 (July 19, 2010) (presenting interim rules issued by Department of Treasury (IRS), Department of Labor (Employee Benefits Security Administration), and Department of Health and Human Services; specifically, interim final regulations with request for comments, implementing the PPACA regarding preventive health services).

105. See id. at 41759 (presenting the text of the HHS rule, 45 CFR Subtitle A, Part 147 - Health Insurance Reform Requirements for the Group and Individual Health Insurance Markets, amending 45 CFR part 147; § 147.130 Coverage of preventive health services). The text of the Department of Labor rule was virtually identical. See id. at 41757--41758 (amending 29 CFR part 2590 by adding to subpart $C$ a new section 2590.715--2713).

106. See id. at 41728.

107. See 76 Fed. Reg. 46621-46626 (Aug. 3, 2011).

108. See Closing the Gaps, supra note 79. 
form of "HRSA Supported Women's Preventive Services," which in turn constitute "Required Health Plan Coverage Guidelines." 109 In adopting the IOM recommendations, HHS adopted, in toto, the IOM claim that contraceptives are necessary to safeguard and improve women's health. The validity of the claim was never addressed or explored in any depth by HHS itself as part of the administrative rulemaking process. ${ }^{110}$ This becomes clear when the requisite agency explanations are scrutinized.

\section{A. The Agency Explanations: Reliance on Expert Advisors}

Two explanations relating to the content of the preventive services were provided by HHS: an explanation supporting the general preventive services mandate, and an explanation tailored to the contraceptive mandate. Together, the explanations show that HHS did not conduct its own study as to the appropriateness of including contraceptive services, but relied on the work of others, predominantly the IOM.

The general explanation: The explanation accompanying the July 2010 Interim Final Rules addressed the need for the preventive services mandate generally. Much of the explanation is not relevant to the question of health benefits flowing from the mandate. ${ }^{111}$ For example, the explanation addressed shortcomings of the health insurance market that dissuade coverage of preventive services; shortcomings that, realistically, do not provide sound reasons to mandate coverage of contraceptives. ${ }^{112}$ The explanation also highlighted studies that show that improved coverage of preventive services

109. See 76 Fed. Reg. 46621, 46623 (Aug. 3, 2011) (explaining that the guidelines would be commonly known as HRSA's Women's Preventive Services: Required Health Plan Coverage Guidelines). But see id. at 46624 (although dated August 3, 2011, HHS states that "no such guidelines have yet been issued ...."). See also 77 Fed. Reg. 8725, 8725 (Feb. 15, 2012). Thus, the religious liberty concerns of the religious communities in fall 2011 were spurred not just by the narrow religious exemption, but also because the full ramifications of the mandate and its impact on religious liberty became clear at about the same time.

110. In fact, HHS never explicitly sought public comment on the issue of what services should be included in the women's preventive services mandate.

111. See 75 Fed. Reg. 41726, 41730 (July 19, 2010) (discussing need as part of the economic impact analysis).

112. See id. at 41731, section $\S \mathrm{IV}(\mathrm{A})$. HHS identified three dissuading factors: high turnover, which would mean that benefits stemming from preventive services (which tend to recouped in the future) may not be realized; the fact that individuals may not actually use preventive services even if offered it, again often because the services do not generate immediate benefits; and the fact that some benefits flowing from use of preventive services accrue to society generally rather than solely to the provider of coverage or the user of the services. None of these reasons are persuasive when considered from the perspective of coverage for contraceptive use or sterilization. The first two reasons pertain to the immediacy of benefit derived from the service. Because the benefit of many preventive services is not immediately recouped, providers and users may not think the cost is justified. The effect of contraceptive use, however, can be monitored and detected on a regular basis. For individuals choosing to use contraceptives, the contraceptive effect can be detected each month that the woman has been sexually active and does not conceive or a pregnancy is avoided. For the insurer or employer, economic benefits are realized every month that costs associated with prenatal care and childbirth are avoided. This same fact vitiates the third reason as well: although contraceptive use may translate into cost savings flowing to society generally, real and timely cost savings are experienced by insurers or employers who provider contraceptive and sterilization coverage. 
leads to expanded utilization. ${ }^{113}$ But, HHS also acknowledged that cost is only one barrier to utilization, and further that "[a] reasonable assumption is that the average increase in utilization of these services will be modest, perhaps on the order of 5 to 10 percentage points for some of them [and, further,] [f]or services that are generally covered without cost sharing in the current market, the Departments would expect minimal change in utilization."114 This acknowledgment also cuts against mandating contraceptive coverage, since contraceptive services are covered by over 85 percent of employersponsored health insurance plans. ${ }^{115}$

But the general explanation did, in part, address health benefits. In doing so, HHS focused on the fact that the mandate would include services recommended by a government agency, ${ }^{116}$ and explained that many preventive services recommended or supported by government entities are in fact associated with health benefits. ${ }^{117}$ HHS noted: "Effective cancer screening, early treatment, and sustained risk reduction could reduce the death rate due to cancer by 29 percent. Improved blood sugar control could reduce the risk for eye disease, kidney disease and liver disease by 40 percent in people with Type 1 or Type 2 diabetes." 118 HHS also highlighted that vaccines have "reduced or eliminated serious diseases that, prior to vaccination, routinely caused serious illnesses or deaths."119 HHS emphasized that it was the shared decision making that would ensure that mandated services promote

113. See id. at 41733 n. 28

114. Id. at 41734 .

115. See, e.g., Brief of Archdiocese of Oklahoma City, at 26, in the appeal to the United States Court of Appeals for the Tenth Circuit, of Hobby Lobby, 870 F.Supp.2d 1278 (W.D. Okla., Nov. 19, 2012) (noting that the government has acknowledged that contraceptive services already are widely available and covered by over $85 \%$ of employer-sponsored health insurance plans). See also Brief of Archdiocese of Indianapolis, 24-25, in the appeal to the United States Court of Appeals for the Seventh Circuit, of Grote Industries, LLC v. Sebelius, 914 F. Supp.2d 943, 2012 WL 6725905 (S.D. Ind., December 27, 2012) and 2013 WL 53736 (S.D. Ind., January 3, 2013).

116. As dictated by the statute, the mandate would include preventive services falling into four different categories: Evidence-based items or services that have in effect a rating of A or B in the current recommendations of the United States Preventive Services Task Force (Task Force); Immunizations for routine use in children, adolescents, and adults that have in effect a recommendation from the Advisory Committee on Immunization Practices of the Centers for Disease Control and Prevention (Advisory Committee) with respect to the individual involved; With respect to infants, children, and adolescents, evidence-informed preventive care and screenings provided for in the comprehensive guidelines supported by the Health Resources and Services Administration (HRSA); and With respect to women, evidence informed preventive care and screening provided for in comprehensive guidelines supported by HRSA (not otherwise addressed by the recommendations of the Task Force). See 75 Fed. Reg. at 41731 (HHS explained that the guidelines were under development, and that HHS expected to issue them no later than August 1, 2011).

117. Id. at 41733 (quoting Woolf, Steven. A Closer Look at the Economic Argument for Disease Prevention. JAMA 2009; 301(5): 536-538).

118. Id. at 41734 (citing Curry, Susan J., Byers, Tim, and Hewitt, Maria, eds. 2003. Fulfilling the Potential of Cancer Prevention and Early Detection (Washington, DC: National Academies Press); See Centers for Disease Control and Prevention, Diabetes at a Glance(2010) available at, http://www.cdc.gov/ chronicdisease/resources/publications/aag/pdf/2010/diabetes_aag.pdf.).

119. Id. (citing Modern Infectious Disease Epidemiology by Johan Giesecke 1994, Chapter 18, The Epidemiology of Vaccination). 
health. ${ }^{120}$ Specifically, HHS explained:

The preventive services given a grade of A or B by the Task Force have been determined by the Task Force to have at least fair or good evidence that the preventive service improves important health outcomes and that benefits outweigh harms in the judgment of an independent panel of private sector experts in primary care and prevention. Similarly, the mission of the Advisory Committee is to provide advice that will lead to a reduction in the incidence of vaccine preventable diseases in the United States, and an increase in the safe use of vaccines and related biological products. The comprehensive guidelines for infants, children, and adolescents supported by HRSA are developed by multidisciplinary professionals in the relevant fields to provide a framework for improving children's health and reducing morbidity and mortality based on a review of the relevant evidence. The statute and interim final regulations limit the preventive services covered to those recommended by the Task Force, Advisory Committee, and HRSA because the benefits of these preventive services will be higher than others that may be popular but unproven. ${ }^{121}$

HHS's point was that services would be included in the mandate only after a rigorous risk/benefit assessment: i.e., only if-based on a review of the relevant evidence (and presumably sufficiently reliable and probative evidence) - the evidence shows genuine health benefits, that the benefits outweigh the potential harms, and that the benefits of services included in the mandate would be higher than benefits of other comparable preventive services (e.g., other services effective at preventing the targeted health condition). The assessment would be conducted by expert advisors, but HHS would have a role: that of ensuring the assessment satisfied the expected standard.

The explanation for the contraceptive mandate: The Amended Interim Final Rules issued August 3, 2011, presented HHS's proposed exemption for religious employers. ${ }^{122}$ Although HHS had received the IOM recommendations, and had decided to adopt the IOM recommendations, the August 3rd notice still did not address the health based justification for including contraceptive services. HHS noted only that many commenters recommended inclusion of contraceptives - and, as well, recommended making the coverage requirement binding on all group health plans and health insurance issuers with no religious exemption. ${ }^{123}$ HHS thus portrayed its very narrow exemption as being a reasonable accommodation between two opposing positions.

120. "[T]hese interim final regulations limit preventive service coverage under this provision to services recommended by the Task Force, Advisory Committee, and HRSA." 75 Fed. Reg. 41733 (July 19, 2010).

121. Id. at 41733(emphasis added); see also USPSTF A and B Recommendations, U.S. Preventive Services Task Force available at, www.uspreventiveservicestaskforce.org/uspstf/uspsabrecs.htm (last visited Jun. 4, 6/4/2012); See also 75 Fed. Reg. 41741-744 (presenting the list dated July 13, 2010). (emphasis added).

122. See 76 Fed. Reg. 46621 (Aug. 3, 2011).

123. Id. at 46623 . 
The Final Rule issued February 15, 2012, retained the very narrow religious exemption, ${ }^{124}$ and, in support of this decision HHS presented an explanation that finally addressed, to some extent, the issue of the need for the contraceptive mandate from the perspective of health. ${ }^{125} \mathrm{HHS}$ first reiterated the basic explanation for a preventive services mandate: HHS noted that elimination of cost sharing makes it somewhat more likely that individuals will use preventive services, and that "[u]se of preventive services results in a healthier population and reduces health care costs."126 Regarding congressional intent, HHS stated (i) that Congress determined that coverage of preventive services without cost sharing "is necessary to achieve basic health care coverage" - which is simply saying that basic insurance coverage should cover preventive services without cost sharing; and (ii) that, by including a provision relating to health care for women, Congress "recognized that women have unique health care need and burdens."127 HHS then asserted the conclusion that women have unique health care needs, including the need for contraceptive services. ${ }^{128}$ In support of this conclusion HHS pointed to the IOM's recommendations ${ }^{129}$ and stated:

[W]omen experiencing an unintended pregnancy may not immediately be aware that they are pregnant, and thus delay prenatal care. They also may not be as motivated to discontinue behaviors that pose pregnancy-related risks (e.g., smoking, consumption of alcohol). Studies show a greater risk of preterm birth and low birth weight among unintended pregnancies compared with pregnancies that were planned. Contraceptives also have medical benefits for women who are contraindicated for pregnancy, and there are demonstrated preventive health benefits from contraceptives relating to conditions other than pregnancy (e.g., treatment of menstrual disorders, acne, and pelvic pain). ${ }^{130}$

These few sentences constitute the totality of HHS's explanation relating to the health benefits of contraceptives. ${ }^{131}$ These few sentences focus on the

124. See 77 Fed. Reg. 8725 (Feb. 15, 2012).

125. Although the explanation does not flesh out the religious liberty concerns (and at best seems to acknowledge only that, if the mandate perhaps interferes with religious liberty, it does so only minimally), HHS nonetheless asserted that the mandate is consistent with Congress' intent in passing the women's preventive services amendment and, further, that any interference with religious liberty is justified by "compelling public health and gender equity goals." Id. at 8729 .

126. 77 Fed. Reg. 8727 (Feb. 15, 2012).

127. Id. at 8727 .

128. Id. at 8727 .

129. Id. at 8727 (citing Inst. Of Med., Clinical Preventive Services for Women: Closing the Gaps, (WASH. D.C.: NAT'L ACAD. PRESS, 2011, at 9)). HHS also cited Adam Sonfield, A., The Case for Insurance Coverage of Contraceptive Services and Supplies Without Cost Sharing, 14 GUTTMACHER POL'Y REV. 10 (2011), available at http://guttmacher.org/pubs/gpr/14/1/gpr140107.html). Id.

130. Id. at 8727 (citing J.D. Gipson, J.D., et al.,, The Effects of Unintended Pregnancy on Infant, Child, and Parental Health: A Review of the Literature, STUDIES ON FAMILY PLANNING, 39(1):18--38 (2008), ; Inst. Of Med., Closing the Gaps, at 107).

131. The remainder of HHS's explanation, supported primarily by input from the Guttmacher Institute, relates to cost savings flowing to employers (the cost of contraceptives tends to be less than medical costs and productivity losses associated with pregnancy); and social and economic benefits 
idea that contraceptives help women avoid pregnancies, and, in particular what IOM has characterized as unintended pregnancies; and also can be prescribed to alleviate non-pregnancy medical disorders. Because most health plans cover prescription drugs used to treat medical disorders and religious groups opposed to use of contraceptives are opposed only to use of contraceptives for contraceptive purposes, the relevant aspect of HHS's explanation relating to the health benefits of contraceptive use is reduced to one point: women need contraceptives to avoid unintended pregnancy. And as to this point, HHS relied solely on the work of other entities. Specifically, HHS predominantly relied on the 2011 IOM Report detailing the IOM recommendations for the services to be included in the mandate - which in turn relied on other work, namely, guidelines of the American Congress of Obstetricians and Gynecologists, and a 1995 IOM publication focused solely on a particular constructed concept of "unintended pregnancy."132 Scrutiny of these sources reveals significant shortcomings; shortcomings that seriously undermine an assertion that contraceptive services are essential for women's health. And shortcomings that show HHS did not live up to its role of ensuring that the risk/benefit assessment by expert advisors served its purpose: that of limiting the mandate to services that in fact promote women's health and are not merely popular services.

\section{B. The 2011 IOM Report}

According to HHS's July 2010 general explanation, limiting the coverage mandate for women's preventive services to those supported by HRSA would ensure that the mandated services would genuinely promote health and would not be merely popular services. Specifically, HHS claimed the approach would help ensure that the services selected would be developed with input from professionals with appropriate expertise, and would be based on a review of all the relevant evidence showing genuine health benefits and that the benefits outweigh the potential harms. HSRA, however, had virtually no role in the development of the designated services. Rather, HHS delegated the central role in developing the guidelines for women's preventive services - and thus the analytical legwork - to the Institute of Medicine. ${ }^{133}$

flowing to women (by virtue of being able avoid pregnancy, contraceptives allow women "to achieve equal status as health and productive members of the job force"). Id. at 8728 (citing Testimony of Guttmacher Inst., submitted to the Comm. on Preventive Servs. for Women, Inst. of Med., Jan. 12, 2012, p. 6 (citing C Goldin C \& Land Katz L, Career and marriage in the age of the pill, AM. ECON. REV. 90(2):461-465 (2000), 90(2):461-465; C Goldin C \&and LF Katz LF, The power of the pill: oral contraceptives and women's career and marriage decisions, J. OF POL. ECON. 110(4):730-770 (2002), 110(4):730-770; and MJ Bailey MJ, More power to the pill: the impact of contraceptive freedom on women's life cycle labor supply, Q. J. OF ECON., 121(1):289-320 (2006, 121(1):289-320)).

132. The 2011 IOM Report expressly cites to and draws from the 1995 IOM publication. The 1995 publication is scrutinized infra Part III(D). HHS also relied on literature issued under the umbrella of the Guttmacher Institute.

133. More specifically, HHS delegated the task of developing guidelines to the Office of the Assistant Secretary for Planning and Evaluation (ASPE) within HHS, and ASPE in turn provided funds 
The key language of the charge to IOM directed IOM to convene an expert committee to "review what preventive services are necessary for women's health and well-being and should be considered in the development of comprehensive guidelines for preventive services for women . . . . and to highlight specific services and screenings that could supplement currently recommended preventive services for women."134 IOM was thus directed to identify preventive medical services needed by women that would supplement preventive services given a grade of A or B by the U.S. Preventative Services Task Force (Task Force). In response, IOM formed the Committee on Preventive Services for Women. ${ }^{135}$ This Committee devised a methodology and the parameters for its work. Study of the methodology and its application as it pertains to contraception services shows that the Committee's work fell short of the rigorous assessment promised by HHS and, instead, shows uncritical reliance on advocacy driven positions.

\section{1) The Methodology of the Committee and the Dissenting Opinion}

The Committee on Preventive Services for Women (CPSW) took a broad approach to identifying gaps in existing Task Force recommendations. It defined preventive health services as "measures - including medications, procedures, devices, tests, education and counseling - shown to improve wellbeing, and/ or decrease the likelihood or delay the onset of a targeted disease or condition."136 Subcommittees assembled and studied relevant evidence for a number of identified potential preventive measures, and presented their analyses to the full CPSW; and the recommendations reflect the judgment and consensus of the Committee. ${ }^{137}$ Because services to be included were intended to supplement recommendations of the Task Force, CPSW - with the administration's approval - decided the process used by CPSW need not conform to that used by the Task Force. The key import of this decision was that the recommendations could have a less definitive, or less weighty, evidentiary basis. ${ }^{138}$ Nonetheless, CPSW saw "assembling the evidence" for the

to the IOM to make recommendations. See Closing the Gaps, supra note 79, at 20-21.

134. Id. at 21 (Box 1-2). The committee was also charged with providing guidance regarding how to keep the list of women's preventive services up-to-date. The committee was to focus on services specified for clinical settings and applicable to females aged 10-65 years; and the cost-effectiveness of screenings of services could not be a factor in the analysis leading to the committee recommendations. Id. at 2-3. The charge explained that ASPE would use information and recommendations from IOM to guide policy making related to the ACA. Id. at 12 (Box 1-2). That HHS adopted the IOM recommendations, in toto, with less than two weeks of study, is evidence of a preordained decision.

135. Id. at 2 (the committee convened by IOM had 16 members, including experts in disease prevention, women's health issues, adolescent health issues, and evidence-based guidelines).

136. Id. at 3 (Box 1-2), Id. at 23 (Box 1-3).

137. Id. at 6-7.

138. ASPE confirmed that CPSW could rely on "bodies of evidence beyond systematic evidencebased reviews." Id. at 3. CPSW reviewed relevant USPSTF publications, but also assembled and reviewed literature reviews, federal health priority goals, federal reimbursement policies, existing coverage practices of private health plans, and the clinical guidelines of health care professional organizations. Id. at 3-5. CPSW also reviewed comments submitted, and invited certain researchers and 
recommendations as the core of its work. ${ }^{139}$

A key aspect of the assessment process involved deciding what type of evidence would be considered. CPSW decided to rely on four categories of evidence: high-quality systemic evidence reviews indicating that the service is effective in women; quality peer-reviewed studies demonstrating effectiveness of the service in women; identification of the measure as a federal priority relating to women's health; or existing federal, state, or international practices, professional guidelines, or federal reimbursement policies that support use of the measure. ${ }^{140}$ As explained in the 2011 Report to HHS, the decision regarding a particular preventive service hinged on balancing "the burden of the condition and its potential impact on health and well-being" against the array of available evidence. ${ }^{141}$ In other words, the greater the perceived or potential burden of a targeted disease or condition, the less weighty the evidentiary support could be.

Notably, the 2011 IOM Report included a dissenting opinion. The dissenting member was concerned, in part, that the very short time frame imposed on the CPSW prevented meaningful review of the evidence. ${ }^{142}$ But the dissent also emphasized problems associated with use of "less weighty" evidence, e.g., the difficulty of identifying "quality" peer-reviewed studies because "many studies published in peer-reviewed journals (even very well respected journals) are low quality and are not generalizable," and the selfserving nature of guidelines put forth by professional organizations. ${ }^{143}$ The evidentiary support for the recommendations thus could, in reality, be very weak. Additionally, the dissent was troubled by the extent to which the recommendations hinged on the subjective judgments of the experts on the committee. According to the dissent:

Readers of the Report should be clear on the fact that the recommendations were made without high quality, systematic evidence of the preventive nature of the services considered. Put differently, evidence that use of the services in question leads to lower rates of disability or disease and increased rates of wellbeing is generally absent. The view of the dissent is that the committee process for evaluation lacked transparency and was largely subject to the preferences

leaders of organizations to deliver presentations. Id. at 5. CPSW acknowledged, however, that time and resource constraints precluded CPSW from conducting meta-analyses and/or comprehensive systematic review of each preventive service considered. Id. at 6 .

139. Id. at 6 .

140. Supposedly, the committee used these queries solely as a means to ensure consistency in its analysis, and full consideration of the range existing evidence that might support a recommendation. Id. at 7.

141. Id. at 7 .

142. Id. at 231 (dissenting opinion by Anthony Lo Sasso, Professor and Senior Research Scientist, Division of Health Policy and Administration, University of Illinois at Chicago School of Health Policy). The report was due to HHS approximately six months from the time the committee was empanelled. $I d$. at 232. The committee met five times in six months, and held three open informationgathering sessions. $I d$. at 3 . The dissent also expressed concern about the inability to consider the recommendations from the perspective of whether an insurance mandate was a good policy decision. Id. at 233 .

143. Id. at 232 (dissenting opinion). 
of the committee's composition. Troublingly, the process tended to result in a mix of objective and subjective determinations filtered through a lens of advocacy. ${ }^{144}$

As explained infra, signals of such advocacy are apparent when the report is critically studied - particularly in regard to the treatment of contraceptive services.

The IOM Report acknowledged the somewhat subjective nature of the decision making process, but CPSW nonetheless asserted the process was sound. In particular, CPSW highlighted that the recommendations met the following criteria:

The condition to be prevented affects a broad population [presumably meaning a group within the overall population of women aged 10-65 years];

The condition to be prevented has a large potential impact on health and well-being; and

The quality and strength of the evidence is supportive. ${ }^{145}$

CPSW emphasized that its recommendations were based on "thoughtful review and debate" and on evidence the committee found "to be compelling." 146

Clearly, however, the stated criteria are much looser. In fact, it is not clear what the last bullet-point means. Basically, the methodology was designed simply to identify "sufficient" supportive evidence, and what would be sufficient would depend on the disease or condition targeted. The greater the perceived or potential burden of a targeted disease or condition, the less weighty the evidentiary support could be. In addition to the concerns stressed by the dissenting member, the criteria thus do not clearly comport with the charge to identify preventive services "needed" for women's health, nor conform to HHS's stated expectation that services would be included in the mandate only if - based on a review of the relevant evidence (and presumably sufficiently reliable and probative evidence) - the evidence shows genuine health benefits and that the benefits outweigh the potential harms.

144. Id. at 232-233 (emphasis added). The CPSW response noted that the dissenting member wanted "more time and the opportunity to incorporate cost-benefit analysis" - which APSE stated should not be a factor in the CPSW analysis leading to the recommendations. Id. at 235 (Response to Dissenting Statement) (see also id. at 3). As noted, the CPSW explained in the body of the report that the subjective nature of the determinations as acceptable and that its approach to the evidence was warranted because it did not have to use the methodology used by USPSTF. CPSW also noted that its study of recommendations of professional organizations included the development of the guidelines and the evidence that the organizations used to reach their conclusions. Id. at 6 .

145. Id. at 8,77 .

146. Id. 
2) Flaws Apparent in Application

CPSW recommended for inclusion in women's preventive services "the full range of Food and Drug Administration-approved contraceptive methods, including sterilization procedures, and patient education and counseling for women with reproductive capacity." 147 According to its methodology, then, CPSW had to find "sufficient evidence" that the preventive measures - contraception and sterilization - improve the well-being of women and/or decrease the likelihood or delay the onset of a "targeted disease or condition" that has a "large potential impact on health and well-being" and that affects a "broad population."148

As is reflected in HHS's explanation of the Final Rule, the condition targeted by the CPSW recommendation is unintended pregnancy, and here it is clear that CPSW drew heavily on the 1995 IOM publication on unintended pregnancy. ${ }^{149}$ To fit its criteria CPSW had to find that the potential health impact of the targeted condition affects a broad population. Meeting this factor hinged on CPSW's broad approach to the condition. Following the approach of the 1995 IOM publication, CPSW defined unintended pregnancy as an unwanted or mistimed pregnancy at the time of conception. ${ }^{150}$ As explored infra, this approach is unnecessarily expansive and facilitates an exaggerated characterization of the "problem of unintended pregnancy."151 But, as defined, the rate of the targeted condition is prevalent: the report states that, in 2001, an estimated 49 percent of all pregnancies in the United States were unintended. ${ }^{152}$ According to the committee, the risk factors for unintended pregnancy - defined in this way - are "female gender and reproductive capacity." 153 Given this extraordinarily broad approach to the issue, CPSW concluded (citing a Guttmacher Institute publication using a similarly broad approach) that the need for preventive measures was great: "In 2008, approximately 36 million US women of reproductive age ... were estimated to be in need of family planning services because they were sexually active, able to get pregnant, and not trying to get pregnant."154

Lastly, the methodology required a finding of sufficient evidence relating

147. Id. at $109-110$ (recommendation 5.5)

148. Id. at 3 (definition of preventive services).

149. CPSW expressly cited the IOM publication. See, e.g., id. at 103 (citing "IOM, 1995").

150. Id. at 102 (citing Finer and Hinshaw, Disparities in rates of unintended pregnancy in the US, in 1994 and 2001, in Perspectives on Sexual and Reproductive Health, 38(2): 90-96 (2006)). Finer and Hinshaw are associated with the Guttmacher Institute. See infra note 144 and note 146. Additionally, this is essentially the definition adopted by the 1995 IOM publication. See infra note 243 and accompanying text.

151. See infra Part III(D)(2).

152. Closing the Gaps, supra note 79 , at 102.

153. Id. at 103 .

154. Id. at 103 (citing Frost, J.J., S.K. Henshaw, and A. Sonfield, Contraceptive needs and services: National and state data, 2008 update (New York: The Guttmacher Institute, 2010). CPSW also pointed to the large percentage of US women (99\%) who "have ever had sexual intercourse with a male" and used "at least one contraceptive method," which of course just speaks to the popularity of contraceptives. 
to the efficacy of contraceptives. The CPSW recommendation depends on the usual logic linking contraception to women's health. The problem is unintended pregnancy. The preventive measure is family planning, and hence contraception. CPSW states:

Family planning services are preventive services that enable women and couples to avoid an unwanted pregnancy and to space their pregnancies to promote optimal birth outcomes. A wide array of safe and highly effective FDA-approved methods of contraception is available, including barrier methods, hormonal methods, emergency contraception, and implanted devices; sterilization is also available for women and men. This range of methods provides options for women depending upon their life stage, sexual practices, and health status. ${ }^{155}$

To support a finding that sufficient evidence exists showing the preventive measure (contraceptives) decreases the likelihood of the targeted condition (unintended pregnancy), CPSW focused only on data showing that contraception is effective at reducing unintended pregnancy. ${ }^{156}$

The work of CPSW thus reveals significant flaws. First, it is clear CPSW did not consider all the relevant evidence. The methodology requires only evidence subjectively judged to be sufficiently supportive of the recommendation and, as highlighted by the BCPI brief, CPSW ignored studies and decades of experience which cast considerable doubt on the premise that contraceptives are an effective strategy against the perceived "problem" of "unintended pregnancy." 157 Second, the many and serious health risks associated with contraceptive use were virtually ignored by CPSW. The report states:

As with all pharmaceuticals and medical procedures, contraceptive methods have both risks and benefits. Side effects are generally considered minimal. Death rates associated with contraceptive use are low and, except

155. Id. at 105 (citation omitted) (stating also: “Some methods, such as condoms, spermicides, and emergency contraceptives, are available without a prescription, whereas the more effective hormonal and long-acting reversible methods, such as oral contraceptives and intrauterine devices, are available by prescription or require insertion by a medical professional."). CPSW also pointed to nonpregnancy related benefits associated with use of oral hormonal contraceptives. $I d$. at 107. But, this benefit would seem to be irrelevant to an assessment for purposes of the preventive services mandate. Also, although the report devotes more attention to the question of evidentiary support (approximately $4 \frac{1}{2} 2$ pages of text), the report includes a rather substantial discussion of the cost-effectiveness of contraceptives (approximately 2 pages). The key aspect of a cost-effective analysis of contraceptives is the fact that the medical costs associated with contraceptives are relatively inexpensive when compared with medical costs associated with pregnancy and childbirth; and that a most insurance plans and employers offer coverage for contraceptives.

156. CPSW pointed to studies showing the effectiveness of contraceptives (e.g., greater use of contraception within the population produces lower unintended pregnancy); and studies suggesting "negligible" failure rates with "proper use." Id. at 105 (citing, inter alia, Boonstra, H.D., R.B. Gold, C.L. Richards, and L.B. Finer, Abortion in women's lives (New York: The Guttmacher Institutes, 2006)).

157. See supra notes $79-88$ and accompanying text. 
for oral contraceptive users who smoke, lower than the U.S. maternal mortality rate. ${ }^{158}$

However, specific serious known health risks and their prevalence were not addressed at all. Instead, as explained infra, CPSW here simply relied uncritically on the work of others which downplays health risks associated with contraceptive use. In essence, CPSW essentially deemed FDA approval for marketing to be sufficient evidence supporting the recommendation.

It was its methodology that allowed CPSW to ignore relevant but not supporting evidence and experience, and to gloss over serious known health risks. CPSW merely had to find "sufficient" evidence "supporting" the view that the preventive measures - contraception and sterilization - would decrease the likelihood or delay the onset of a "targeted disease or condition" pregnancy. ${ }^{159}$ In particular, the methodology did not designate "health risks" as a distinct factor to consider. Arguably, this methodology may suffice for other preventive services. Other preventive services are screening and diagnostic services for the detection of life-threatening diseases or conditions such as breast cancer, cervical cancer, ovarian cancer, liver cancer, and heart and vascular diseases. ${ }^{160}$ Screening and diagnostic services generally do not disrupt the normal and healthy operation of human bodily functions, and thus do not entail serious health risks. Some vaccinations carry risks, but they are included in the coverage mandate only upon passing a more rigorous risk/ benefit assessment. ${ }^{161}$ But, contraceptive services are distinguishable. Contraceptives do not identify or prevent serious diseases or illnesses. Instead, popular hormonal contraceptives work by disrupting or distorting a woman's normal and healthy reproductive system in an attempt to prevent the normal and natural consequence of engaging in sexual activity. And, because of this distinct aspect, they pose serious health risks in and of themselves. ${ }^{162}$

In the context of family planning the CPSW methodology allows one effective means of prevention to be elevated to a position of being "the necessary means of prevention," and nothing in the methodology assesses whether the benefits of a service are higher than benefits of other comparable services, or guards against inclusion of merely popular services. By relying on the fact of FDA approval rather than addressing the serious known health risks associated with many contraceptives, the CPSW methodology allowed CPSW to

158. Closing the Gaps, supra note 79, at 105, 107 (noting that the death rate per 100,000 users under age 35 years who are nonsmokers was " 1.5 per 100,000 live births, compared with 11.2 maternal deaths per 100,000 live births in 2006 (age adjusted)" (citing American Congress of Obstetricians and Gynecologists (ACOG), education pamphlets AP021 (birth control pills), AP114 (emergency contraception), AP159 (implants, injections, rings and patches) (Washington, D.C.: ACOG, 2011). The scanty discussion of risks seems egregious when the report includes a rather substantial discussion of a factor supposedly not relevant to the CPSW analysis, namely, the cost-effectiveness of contraceptives (approximately 2 pages).

159. Id. at 3 (definition of preventive services).

160. See, e.g., 75 Fed. Reg. at 41734 .

161. See, e.g., id. at 41733 (discussing the evidence needed to support recommended vaccinations).

162. See infra notes 202-221, 157-178 and accompanying text. 
sidestep the essence of the task it was assigned - the task of identifying preventive services needed to promote women's health, and preventive services that genuinely promote health and are not merely popular services. FDA approval means only that the drugs have been found safe enough to be marketed and thus safe enough to be prescribed for use by women who choose to assume the health risks. ${ }^{163}$ FDA approval does not constitute evidence that contraceptive use genuinely promotes women's health, or that it is necessary to achieve the health benefits of family planning. Significant flaws, then, are apparent in CPSW's application of its methodology to contraceptive services.

\section{3) Evidence of a Pre-Ordained Perspective}

In the context of family planning the highlighted flaws seem linked to a perspective (or ideology) that simply equates contraceptives with family planning. In the report, CPSW summarizes the usual health concerns addressed with family planning strategies. ${ }^{164}$ Planning for pregnancies is a healthy and responsible behavior. But CPSW then focuses not on how to improve family planning, but only on the concept of unintended pregnancy. CPSW does not expressly assert that contraceptives are "necessary" for family planning, but the report does not consider any alternative. CPSW simply states: "Family planning services are preventive services that enable women and couples to avoid an unwanted pregnancy and to space their pregnancies to promote optimal birth outcomes. A wide array of safe and highly effective

163. See 21 U.S.C. $§ 355$ (d) \& (e) (setting out standards for when the Secretary may refuse to approve an application for marketing a drug).

164. For example, CPSW explained that women experiencing unintended pregnancy may not immediately be aware that they are pregnant and thus their entry into prenatal care may be delayed; may not be motivated to discontinue behaviors that present risks for the developing unborn child; and may experience depression, anxiety, or other conditions. Closing the Gaps, supra note 79, at 103 (citing "IOM, 1995"). CPSW explained that pregnancy spacing also is important because a pregnancy within 18 months of a prior pregnancy increases certain adverse pregnancy outcomes. Id. at 103. Timing of pregnancies is also very important for women with some chronic conditions that should be stabilized prior to pregnancy (e.g., diabetes and obesity); and pregnancy is contraindicated for women with some medical conditions (e.g., pulmonary hypertension, cyanotic heart disease, Marfan Syndrome). $I d$. at 103-04. Unintended pregnancies may pose risks for the child as well: CPSW notes that children born as a result of unintended pregnancy are less likely to be breast fed, and odds increase for pre-term birth and low birth weight. Id. at 103. HHS's reliance on these CPSW findings is clear. It is also clear that these findings parallel - albeit with greater specificity - the health concerns identified in the National Prevention Strategy (NPS); health concerns supporting the identification of family planning as being important to women's health. See National Prevention Council, National Prevention Strategy (Washington, DC: US Department of Health and Human Services, Office of the Surgeon General, June 2011) (hereinafter Nat'1 Prev. Strategy). Based on a study of the NPS, planning for pregnancies can be characterized as important to women's health - at least if planning is understood in terms of activities that help ensure that women are healthy when they conceive and sufficiently responsible, specifically, responsible enough (i) to be alert to the possibility of conception if they are sexually active, and (ii) to maintain a healthy lifestyle and access available prenatal care during a pregnancy (which in turn would often include activities that help ensure that women delay conception and pregnancy until they are sufficiently responsible to do the things that foster good health outcomes). Stated more generally, planning for pregnancy can help ensure that conception is delayed until women are willing and able to adopt health-promoting behaviors prior to and during pregnancy. However, CPSW focuses not on family planning, but on unintended pregnancy. 
FDA-approved methods of contraception is available ..." 165 In particular, CPSW ignores a feasible alternative method that many find superior to contraceptives, namely, the fertility awareness method of family planning: an approach to family planning which is as effective and easy to use as the most popular hormonal contraceptive - the pill - and, that achieves family planning with much lower costs and without the serious health risks associated with most contraceptive drugs and devices and without requiring the woman to bear the entire burden associated with effective family planning. ${ }^{166}$ The significance of CPSW's myopic vision can be better appreciated with a brief discussion of the significant and serious health risks associated with contraceptive use, and of the feasibility and effectiveness of the fertility awareness method of family planning - i.e., two key matters which CPSW failed to address.

\section{a) Recent Scientific Studies Demonstrating Serious Health Risks}

In recent years there have been published a growing number of peer-reviewed scientific research papers highlighting serious health risks associated with use of hormonal contraceptives. This body of recent research should have provided a clear signal as to the importance of the risk/benefit assessment expected by (or purportedly expected by) HHS, and ignoring the research is evidence of a pre-ordained perspective on the part of CPSW.

As highlighted in the BCPI Brief, statistical information about the serious health risks associated with hormonal contraceptives paints a stark picture. The BCPI brief emphasized several significant health risks associated with use of hormonal contraceptives. ${ }^{167}$

higher risk of heart attack (doubling the risk for those with no other risk factors, and increasing the risk up to 23 times for those with risk factors);

higher risk of stroke (tripling the risk for those with no other risk factors, and increasing it more for those with risk factors);

higher risk of cervical cancer (a three-fourfold increased risk);

higher risk of liver tumors or cancer; and

greater susceptibility to sexually transmitted diseases (e.g., twice as likely to be infected with genital human papillomavirus virus); ${ }^{168}$ and

as to the newer longer-lasting contraceptives, additional serious risks. ${ }^{169}$ Other work confirms the BCPI assessment. A very helpful compilation

165. See Closing the Gaps, supra note 79, at 138.

166. See infra notes $182-197$ and accompanying text.

167. See also supra Part III(D)(2).

168. See BCPI Brief, supra note 79, at 23-27 (citing numerous peer-reviewed sources). See also WST Brief, O'Brien, supra note 87, at 7-11; WST Brief, Belmont Abbey, supra note 87, at 12-16.

169. BCPI Brief, supra note 79, at 27-31 (citing numerous peer-reviewed sources). See also WST Brief, O'Brien, supra note 87, at 11-15: WST Brief, Belmont Abbey, supra note 87, at 16-21. 
of statistical data is provided in a February 2012 article in the Linacre Quarterly. ${ }^{170}$ The article explains that the low dose pill is associated with a three to five times higher rate of venous thromboembolism (and also with higher rates of fatal pulmonary embolism), ${ }^{171}$ and that recent studies also strongly suggest that the risk of VTE is significantly higher with the newer generation of combination hormonal methods (e.g., certain pill formulas, the patch, the vaginal ring). ${ }^{172}$ In addition, the article reports that studies show that use of low dose oral contraceptives increases the risk of myocardial infarction by 200 percent (and that the risk is increased even more if a woman smokes or has some level of hypertension), ${ }^{173}$ and show that the increased risk of stroke is substantial; 174 and also confirm that these risks are magnified in women who smoke (e.g., the risk of myocardial infarction increases tenfold), ${ }^{175}$ for smokers over age 35, and for women who suffer from migraines. ${ }^{176}$ And, again, the risks may be greater for high newer, long-lasting or higher dose formulations.

In addition, as the BCPI brief emphasized, research also shows a documented association between hormonal birth control options and breast cancer. BCPI explains:

A meta-analysis published in 2006 showed a $44 \%$ increased risk of breast

170. The Linacre Quarterly is the official journal of the Catholic Medical Association. Continuously published since 1934, The Linacre Quarterly is the oldest journal in existence dedicated to medical ethics.

171. See Rebecca Peck, Significant Risks of Oral Contraceptives: Why This Drug Class Should Not be Included in a Preventive Care Mandate, The Linacre Quarterly 79(1) (February 2012), 43-44 (citing Practice Committee of the American Society for Reproductive Medicine, "Hormonal Contraception"; V.A. Van Hylckama et al., "The Venous Thrombotic Risk of Oral Contraceptives, Effects of Estrogen Dose and Progestogen Type: Results of the MEGA Case-Control Study," British Medical Journal 339 (2009):b2921; N.R. Poulter, "Risk of Fatal Pulmonary Embolism with Oral Contraceptives," Lancet 355 (2000):2088)). The risk of VTE is even higher for women with hereditary thrombophilia - and women generally are not aware of carrying the mutation until they take the pill and suffer consequences. $I d$. at 44 .

172. Id. at 44 (citing FDA, "FDA Drug Safety Communication: Safety Review Update on the Possible Increased Risk of Blood Clots with Birth Control Pills Containing Drospirenone" (2011) (accessible at http:/ / www.fad.gov/Drugs/DrugSafety/ucm273021.htm)).

173. Id. at 45 (citing Practice Committee of the American Society for Reproductive Medicine, "Hormonal Contraception: Recent Advances and Controversies," Fertility and Sterility 82 (2004):520526; WHO Collaborative Study of Cardiovascular Disease and Steroid Hormone Contraception, "Acute Myocardial Infarction and Combined Oral Contraceptives: Results of an International Multicentre Case-Control Study," Lancet 349 (1997):1202-1209; K,M. Curtis et al., Combined Oral Contraceptive Use Among Women with Hypertension: A Systematic Review, Contraception 73 (2006):179188)).

174. Id. at 45 (citing Committee of the American Society for Reproductive Medicine, "Hormonal Contraception: Recent Advances and Controversies," Fertility and Sterility 82 (2004):520-526; WHO Collaborative Study of Cardiovascular Disease and Steroid Hormone Contraception, "Hemorrhagic Stroke, Overall Stroke Risk, and Combined Oral Contraceptives," Results of an International Multicentre Case-Control Study," Lancet 348 (1996):505-510)).

175. Id. at 45 (citing M. Vessey, R. Painter, and D. Yeates, "Mortality in Relation to Oral Contraceptive Use and Cigarette Smoking," Lancet 362 (2003):185-191)).

176. Id. at 45 (citing Committee of the American Society for Reproductive Medicine, Hormonal Contraception: Recent Advances and Controversies, Fertility and Sterility 82 (2004):520-526)). 
cancer in women who took oral contraceptives before having a child. ${ }^{177}$ In 2007, the World Health Organization's International Agency on Research of Cancer (IARC) reported that estrogen-progestin combination drugs (the Pill) were a Group 1 carcinogen for breast, cervical, and liver cancers. ${ }^{178}$ A 2009 study showed a $320 \%$ increase risk of triple negative breast cancer, the most difficult and deadly form of cancer to treat, in women taking oral contraceptives. ${ }^{179}$ Although the risk of uterine and ovarian cancers appears lower for women taking contraceptives, there is four times more breast cancer in women than uterine and ovarian cancers combines. ${ }^{180}$

And, again, the work of others is consistent with BCPI's assessment. Breast cancer is very prevalent in the United States. According to rates obtained from 2005-2007, 122.9/100,000 women will develop breast cancer per year. ${ }^{181}$ Given the much higher incidence rate of breast cancer, even small increases in the relative risk caused by hormonal contraceptives translate into much larger increases in absolute risk of cancer. ${ }^{182}$ And studies exist pointing towards an association between breast cancer and contraceptive use - especially by young women. ${ }^{183}$

The Linacre Quarterly again provides a useful summary of relevant studies - some very recent - identifying an association between hormonal contraceptives and increased risks of breast cancer - especially as to women who took the drugs before a first full-term pregnancy. ${ }^{184}$ The article highlights a 2009 study also cited by BCPI, a study revealing a disturbing connection between oral contraceptive use and triple-negative breast cancer: use for more than one year was associated with a 2.5-fold increased risk, and, for use

177. BCPI Brief, supra note 79, at 24-25 (citing C.Kahlenborn et al., Oral contraceptive use as a risk factor for premenopausal breast cancer: A meta-analysis, 81 Mato Clinic Proc. 1290 (2006)).

178. Id. (citing IARC 2007 Monograph 91. Combined estrogen-progestogen contraceptives and combined estrogen-progestogen menopausal therapy).

179. Id. (citing J. Dolle et al, Risk factors for triple negative breast cancer in women under the age of 45, 18 Cancer Epidemiol. Biomarkers Prev. 1157 (2009)).

180. Id. (citing Cancer Statistics by Cancer Type, Centers for Disease Control).

181. See, e.g., Peck, supra note 172, at 46 (citing National Cancer Institute; Surveillance Epidemiology \& End Results, Cancer Statistics "SEER Stat Fact Sheets: Corpus and Uterus, NOS," http://seer.cancer.gov/statfacts/html/corp.html.; National Cancer Institute; Surveillance Epidemiology \& End Results, Cancer Statistics "SEER Stat Fact Sheets: Ovary", http:/ / seer.cancer.gov/statfacts/html/overy.html), at 45 (citing National Cancer Institute; Surveillance Epidemiology \& End Results, Cancer Statistics "SEER Stat Fact Sheets: Breast," http://seer.cancer.gov/statfacts/html/breast.html)). For additional statistics regarding breast cancer incidence, see http://www.cdc.gov/cancer/breast/statistics/.

182. Peck, supra note 172 , at 46 .

183. The Catholic Medical Association pointed to the link between hormonal contraceptives and breast cancer in its comments submitted to HHS relating to the contraceptive mandate. The CMA comments are accessible at http://www.cathmed.org/issues_resources/publications/press_releases/cma_provides_comments_on_hhs_proposed_accommodation/. Franks explains that claims about a link between hormonal contraceptive use and increased risk of breast cancer are "controversial." See Angela Franks, The Gift of Female Fertility: Church Teaching on Contraception in Women, Sex, and the Church: A Case for Catholic Teaching (edited by Erika Bachiochi) (Pauline Books \& Media: Boston, MA, 2010), at 107 n. 47. This means, of course, that studies suggest an association, but that researchers find ways of explaining the research results away.

184. See Peck, supra note $172,45-49$. 
greater than one year among women younger than forty years, the relative risk of triple-negative breast cancer rose to 4.2. ${ }^{185}$ But other studies are highlighted as well. For example, the Cancer and Steroid Hormone studies showed that women who took the pill prior to their first full-term pregnancy and were under 44 years of age had a 40 percent increased relative risk of developing breast cancer, which reached statistical significance in the 35-44 year-old age group. ${ }^{186}$ Similarly, a recent prospective cohort study at Harvard found that current use of oral contraceptives carries an excess risk of breast cancer, with levonorgestrel accounting for much of the risk. ${ }^{187}$ Other studies also support the existence of a statistical association. ${ }^{188}$

Some may discount the studies highlighting a link between contraceptive use and breast cancer because they show statistical association only. Indeed, the author of the Linacre Quarterly article emphasizes the need for randomized controlled trials to clarify the magnitude of the association - noting that randomized control trials have shown that hormone replacement therapy (which uses estrogen and progesterone derivatives similar to those in birth control pills) increases the risk of breast cancer for postmenopausal women ${ }^{189}$ and that contraceptive use involves ingestion of the drugs for longer periods of time and in stronger doses, and very often by young women with susceptible breast tissue. ${ }^{190}$ However, as pointed out by the BCPI brief, the

185. Id. at 47 (citing J.M. Dolle et al., Risk Factors for Triple-Negative Breast Cancer in Women Under Age 45, Cancer Epidemiology, Prevention and Biomarkers 18 (2009):1157-1166)).

186. Id. at 46-47 (citing P.A. Wingo et al, Age-Specific Differences in the Relationship between Oral Contraceptive Use and Breast Cancer, Cancer 71 (1993):1506-1517)).

187. Id. at 47 (citing D.J. Hunter et al, Oral Contraceptive Use and Breast Cancer: A Prospective Study of Young Women, Cancer Epidemiology, Prevention and Biomarkers 19 (2010): 2496-2502)). See also Isabelle Romieu et al., Oral Contraceptives and Breast Cancer: Review and Meta-Analysis, Cancer 66, no. 11 (Dec. 1, 1990): 2253-63 (cited in Chris Kahlenborn, Breast Cancer: Its Link to Abortion and the Birth Control Pill (Dayton, OH: One More Soul, 2000), 9 (focusing on the risk of using the pill for women using it for more than four years before their first full-term pregnancy, and finding a $72 \%$ increased risk of developing breast cancer).

188. See Peck, supra note 172, at 47-48, notes 36-42 (citations including the largest meta-analysis, comprised of 54 epidemiological studies and including 53,297 women with cancer and 100,239 controls: V. Bjelic-Radisic and E. Petru, Hormonal Contraception and Breast Cancer Risk, Wiener medizinische Wochenschrift 160 (2010): 483-486)). See also Kahlenborn et al., “Oral Contraceptive Use as a Risk Factor for Premenopausal Breast Cancer: A Meta-Analysis," Mayo Clinic Proceedings 81, no. 10 (Oct. 2006): 1290-1302 (showing a 44\% increased risk in developing breast cancer when oral contraceptives are taken before the first full-term pregnancy, with the risk rising to $52 \%$ if the pill is taken for more than four years). Kahlenborn explains that studies that do not show a link generally do not isolate the population that has used oral contraceptives before the first full-term pregnancy. See Chris Kahlenborn, Breast Cancer: Its Link to Abortion and the Birth Control Pill (Dayton, OH:One More Soul, 2000), 36. A useful discussion is also available at the website of The Polycarp Research Institute: "Overview: Breast Cancer and the Pill," accessible at www.polycarp.org (accessed 9/18/2012).

189. See Peck, supra note 172 , at 48 .

190. Id. The author thus asks:

Why have no randomized controlled trials been performed to date? One reason may be that it would not be in the best interest of the pharmaceutical industry to perform such expensive studies, especially if we examine what happened with the HRT experience. Up until 2002, physicians mistakenly recommended HRT to postmenopausal women for cardiovascular health benefits and cancer protection. Once the results of the Women's Health Initiative were publicized in the mainstream media, 
IOM/CPSW position that contraceptive use promotes health by preventing unintended pregnancies is similarly based largely on statistical association and not causation. ${ }^{191}$ Many would find it egregious that IOM and HHS would rely on association and not causation for purposes of mandating coverage for contraceptive use - even in the face of religious objections - but ignore very serious health risks with the same level of proof as to the causal nexus. The inconsistency seems explicable only as evidence of CPSW members (and HHS officials) holding a pre-ordained perspective in favor of contraceptive use; and giving priority to that perspective over sound empirical investigation. Importantly, the point here is not that the health risks associated with hormonal contraceptives mean that contraceptives should not be marketed (that conclusion would depend on more rigorous studies aimed at quantifying the risk with greater precision). Rather, the point is that ignoring the serious health risks undermines the value of the recommendation in the IOM Report because the assessment of CPSW was incomplete.

\section{b) A Highly Effective and Safer Approach for Most Women}

CPSW also ignored a feasible alternative method of family planning that, objectively, seems superior to contraceptive use, namely, the fertility awareness method of family planning (FAM). FAM is considered a scientifically validated, natural method of effective birth control, pregnancy achievement, and health awareness. ${ }^{192}$ It is based on the observation and charting of physical signs scientifically proven to be reliable signals of whether conception is likely on any given day."193 Because a woman is fertile for only a few days each cycle, use of FAM provides an opportunity for very effective family planning without subjecting a woman to risk-producing drugs and devices day-in and day-out for the decades of time when she generally is capable of reproduction.

FAM is based on the biological predictability of a woman's natural reproductive cycle. Although the length can vary (which causes many to believe the cycle is unpredictable), a woman' reproductive cycle is actually incredibly predictable. ${ }^{194}$ Beginning during puberty and continuing through menopause, roughly every 24-36 days a woman's body naturally works to release

prescriptions for HRT dropped by half in just a couple of months.

Id. Given estimates that there are close to a hundred million prescriptions for hormonal oral contraceptives filled worldwide, a more definitely proven link between the pill and breast cancer would have a significant financial impact on pharmaceutical manufacturers.

191. See supra note 83 and accompanying text.

192. See generally Toni Weschler, MPH. Toni Weschler, Taking Charge of Your Fertility: The Definitive Guide to Natural Birth Control, Pregnancy Achievement, and Reproductive Health (New York: William Morrow (An Imprint of HarperCollinsPublishers), 2006) (a comprehensive and understandable source explaining NFP and the fertility awareness method).

193. Id. at 4,9 .

194. The process involves a highly complex system of continuous feedback loops driven by female hormones. Id. at 366, 46-51. The first part of the cycle, from Day 1 of menses to ovulation, is the estrogenic phase. The length of the estrogenic phase can vary due to many factors: stress, travel, 
an egg capable of being fertilized, and to prepare the conditions necessary to nurture an unborn child for the duration of a pregnancy. Ovulation occurs when a mature egg is released through the ovarian wall. When the mature egg is released it is picked up by the fallopian tube and remains alive for a maximum of 24 hours. Fertilization thus must occur in this limited period of time. The fertility window is wider, however, because sperm can live up to five days in fertile-quality cervical fluid. ${ }^{195}$ For purposes of family planning, then, the fertile period is approximately six days per month. ${ }^{196}$ Knowing the day of ovulation is critical for purposes of identifying the fertile period.

The three scientifically validated signs of ovulation are elevated basal body temperature, fertile-quality cervical fluid, and changes in cervical position. ${ }^{197}$ The latter two of these signs reveal impending ovulation, ${ }^{198}$ while a rise in waking temperature indicates that ovulation has already occurred. ${ }^{199}$ By observing and recording the signs, women and couples are able to reliably identify a couple's fertile period and, using the information, decide whether to engage in sexual activity and perhaps conceive a child, or to avoid sexual activity at that time.

FAM thus allows a couple to plan for children without the significant expenses associated with contraceptives, and without subjecting the woman to the serious health risks or negative symptoms associated with most contraceptives. Rather than suppressing or distorting a woman's healthy reproductive system, FAM is grounded in understanding and respecting its natural operation. Importantly, observing and recording the signs of fertility is not a difficult or burdensome task. Although FAM tends to be used more frequently by highly educated women, it is a method that most women are capable of using. ${ }^{200}$ Moreover, it is not more challenging to use than the very popular pill. ${ }^{201}$

moving, illness, medication, strenuous exercise, weight change, etc. Id. at $48,55-56$. The second phase, from ovulation to the last day before another cycle begins with menses, is the progestational phase. This phase typically has a finite span of 12 to 16 days. Knowing the day of ovulation is thus integral to accurately predicting the length of any particular cycle. Id. at 48.

195. Three factors must be present for fertilization - or conception - to occur: the egg, the sperm, and a medium through which the sperm can travel to reach the fallopian tube. The medium is fertilequality cervical fluid, which women produce under the influence of increasing levels of estrogen in the first part of the cycle. Id. at 50.

196. See Allen J. Wilcox et al., Timing of Sexual Intercourse in Relation to Ovulation, 333 THE NEW ENG. J. MED., 1517, 1521 (1995).

197. WESCHLER, supra note 182, at 52. See id. at 52-56 (discussing basal body temperature); Id. at 57-63 (discussing cervical fluid); $I d$. at 63-68 (discussing cervix changes).

198. See id. at 57,64 .

199. Id. at 54 .

200. Toni Weschler, who has spent many years teaching the method to women and couples, knows from experience that "virtually all women can internalize the method and its biological foundation within a few hours," and very few are burdened by the "couple of minutes a day it takes to apply." Id. at 9.

201. The pill is the most popular contraceptive in the United States. See Contraceptive Use in the United States GUTTMACHER INST. (Aug. 2013) http://www.guttmacher.org/pubs/fb_contr_use.pdf (reporting that about $28 \%$ of contraceptive users use the pill). The purported convenience factor likely is a key reason for the popularity of the pill. The reality is different. Both women and their 
FAM also is extremely effective. If the rules are followed and a couple abstains during the fertile phase, use of FAM is as effective as the pill in avoiding pregnancy: the chance of becoming pregnant is approximately two percent over the course of a typical year. ${ }^{202}$ Further, the failure rate of FAM when it is used correctly is substantially better (lower) than the typical user failure rate of the more popular and mainstream birth control methods. ${ }^{203}$ Although user failure rate generally is the more relevant rate, ${ }^{204}$ identifying an accurate user failure rate for FAM is challenging and using that rate is misleading. It is misleading, because, with NFP failure typically occurs only when a couple intentionally decides to violate the rules - namely, by deciding to engage in sexual activity despite obviously present fertile cervical fluid. ${ }^{205}$ Thus, what many would label as FAM "user failure" constitutes, in reality, nonuse: it is more comparable to a decision to not use a condom than to an incorrect attempt to use a condom. ${ }^{206}$ Because user failure rates mask the ef-

healthcare providers cite difficulty of use as a key reason for gaps in contraceptive coverage. See, e.g., Jennifer J. Frost et al., In Brief: Improving Contraceptive Use in the United States. GUTTMACHER INST. (May 2008), http://www.guttmacher.org/pubs/2008/05/09/ImprovingContraceptiveUse.pdf (noting that a majority of providers think that a sizable proportion of their clients experience confusion about correct use or skip two or more pills in a cycle). Further, the influential 1995 IOM publication on unintended pregnancy repeatedly alludes to the difficulty associated with using contraception, and explains:

There is also no doubt that using many of the reversible contraceptive methods correctly and consistently can be very challenging. For example, [a 1994 study] sketched the chain of events that using an oral contraceptives requires a woman to master: obtaining pills, taking them in the correct order, taking each pill within the appropriate time window, abstaining from sex or using a backup method when necessary, obtaining refills on time, stopping one cycle and starting the next at the right time, interpreting problems correctly (neither overreacting nor under-reacting), and taking effective action to resolve problems. Comm. ON Unintended PREgnancy, Div. OF HeAlth PROMOtion AND DisEASE PREVENTION, INST. OF MED. , The Best Intentions: Unintended Pregnancy and the Well-Being of Children and Families 100-01 (Sarah S. Brown \& Leon Eisenberg eds., 1995) [hereinafter The Best Intentions]).

202. See Weschler, supra note 182, app. d at 360,361. Other researchers promote a method of NFP, called the symptothermal method (STM), as being ninety-nine percent effective in avoiding pregnancy. See, e.g., EUROPEAN SOC'Y FOR HUMAN REPROD. AND EMBRYOLOGY, "Natural Family Planning Method as Effective as Contraceptive Pill, New Research Finds," SCIENCEDAILY (Feb. 21, 2007), available at http://www.sciencedaily.com/releases/2007/02/070221065200.htm. In this study, conducted by a team at the University of Heidelberg in Germany, 900 women were tracked and the failure rate was $0.4 \%$. Id. Another significant finding was that the drop-out rate was only $9 \%$, lower than with many other birth control methods. Id.

203. See, Weschler, supra note 182, app. d at 365. Key user failure rates are:

$1-2 \%$ NFP (when the couple abstains)

6-9\%Hormonal contraceptives (injections, the pill or patch, or the vaginal ring)

$15 \%$ Condom (and NFP if the couple does not abstain and uses a condom during the fertile period)

$16 \%$ Cervical cap, sponge, or diaphragm.

$27-29 \%$ Spermicides, withdrawal

$85 \%$ Chance

Weshler explains various reasons why the effectiveness of FAM is not better known (misconceptions, exclusion from medical school curriculum, etc.). Id. at 4-9.

204. Id. app. d at 358 .

205. Id. app. $\mathrm{d}$ at 359-60.

206. Id. at 360. With other methods of birth control, nonuse is segregated from incorrect use and 
fectiveness of FAM, and because inadvertent deviations in observing and recording generally will not result in a failure of the method, FAM's method failure rate $(1-2 \%)$ is a much more accurate reflection of FAM's effectiveness and the more appropriate rate to use for comparative purposes. ${ }^{207}$

As with any method of effective family planning, FAM requires a certain level of discipline and motivation. ${ }^{208}$ Concern that some persons may not be sufficiently mature to "follow the rules" is legitimate, but that concern applies equally to other methods of family planning and it is a concern that lessens substantially once a woman reaches adulthood - and thus is not particularly significant for the vast population of woman whose health needs are being addressed by the preventive services mandate. Furthermore, in addition to being equally effective as, and safer and easier to use than, other popular methods of family planning, FAM also fosters a responsible attitude towards parenthood. This is because, when using FAM, a couple does not lose sight of the natural biological function and operation of a woman's healthy reproductive system. Conception is not likely to occur unless a couple intentionally breaks the rules and thus FAM necessarily confronts a couple with the question whether they are willing and able to care for a child. Given the overall reason that family planning is important to women's health - to help ensure that women are healthy when they conceive, and sufficiently responsible (i) to be alert to the possibility of conception if they are sexually active, and (ii) to maintain a healthy lifestyle and access available prenatal care during a pregnancy - FAM must be recognized as a feasible, very effective, and health-promoting means of family planning.

Nonetheless, despite the evidence demonstrating the efficacy and safety

user failure rates include only incorrect use. This distinction is not made with NFP, meaning that the user failure rates reported in the medical literature misrepresents the effectiveness of NFP. Wischler explains that NFP user failure rates reported in studies vary greatly, "[b]ut what is equally important is that all these studies clearly suggest that in a large percentage of pregnancies that occur while 'using' [NFP], the cause of conception was due to intentional violation of the method rules." Id. at 359-60 (emphasis in original).

207. While some would disagree with Weschler's view of the effectiveness of NFP, some would also disagree with the mainstream view of the effectiveness of the pill. A fact sheet produced by the United States Conference of Catholic Bishops explains that failure rates typically are based on " 12 months of typical use for all women of reproductive age" and this "greatly understates failure rates among teens, and fails to account for cumulative risk from more frequent sexual activity." Fact Sheet: Greater Access to Contraception Does Not Reduce Abortions, U.S. CONFERENCE OF CATHOLIC BISHOPS, http://www.usccb.org/issues-and-action/human-life-and-dignity/contraception/fact-

sheets/greater-access-to-contraception-does-not-reduce-abortions.cfm (last visited Apr. 1, 2014). The fact sheet explains that, "[i]n the first 12 months of contraceptive use, $16.4 \%$ of teens will become pregnant," and further that, "[i]f the teen is cohabitating, the [failure] rate rises to $47 \%$." Id.

208. Weschler, supra note 182, app. $\mathrm{d}$ at 361 . It also is important to emphasize that NFP is a means of family planning and does not prevent or protect against STDs. The best way to prevent STDs is to engage in sexual activity only with trusted and tested partners and/or to use condoms. Given the realities of AIDs and STIs, Weschler recommends use of NFP for monogamous couples with the maturity and discipline to follow the method correctly. Id. at 29. In Catholic teaching, sexual activity and thus NFP is reserved for marriage; this is fully consistent with Weschler's public health considerations. 
of FAM, it is totally ignored by CPSW. ${ }^{209}$ Under the standard set by HHS for inclusion of a service in the mandate, the risk/benefit assessment must include a showing that the benefits of services included in the mandate would be higher than benefits of other services effective at preventing the targeted health condition: i.e., that the health benefits of hormonal contraceptives are higher than health benefits of other effective methods of preventing pregnancy. Ignoring FAM thus undermines the value of the recommendation in the IOM Report because the assessment of CPSW was incomplete. Instead, the work of CPSW reflects the perspective that simply equates family planning with contraceptive use; $; 10$ a perspective that renders it inevitable that analysis of other feasible family planning methods will not occur, and that tends to prevent a person from recognizing that unnecessarily encouraging women to use drugs and devices that pose very serious health risks - day in and day out for decades - logically cannot be a strategy that genuinely promotes women's health.

\section{c) Uncritical Reliance on Sources}

Other evidence also suggests CPSW approached its task from a pre-ordained perspective and gave priority to that perspective over sound empirical investigation. In particular, study of the key sources CPSW employed to support the contraception recommendation reveals uncritical reliance by CPSW on those sources. The sources include advocacy materials produced

209. Notably, in the course of its deliberation, CPSW heard testimony from the Guttmacher Institute that greatly misrepresented the effectiveness of FAM. The Guttmacher Institute explained that family planning is important to women's health, and emphasized: "Contraceptive services and supplies fit any reasonable definition of preventive care, and their effectiveness is supported by a strong body of evidence. Contraception helps women avoid unintended pregnancy and improve birth spacing ...." Testimony of Guttmacher Institute, Submitted to the Committee on Preventive Services for Women, Institute of Medicine, 1 (January 12, 2011), http:/ / www.guttmacher.org/pubs/CPSW-testimony.pdf. The testimony presents effectiveness data of the FDA approved contraceptives, using "typical use failure rates," but greatly exaggerates the failure rate for FAM:

Female and male sterilization, the IUD and the implant all have typical use failure rates of $1 \%$ or less .... The typical use failure rates for injectable and oral contraceptives are $7 \%$ and $9 \%$, respectively, due to some women missing or delaying an injection or pill. The probability of failure for couples using condoms $(17 \%)$ is somewhat higher, again primarily due to imperfect use of the method. And, the failure rate for couples using fertility-awareness-based methods results is [sic] even higher $(25 \%) \ldots$

$I d$. at 2. The failure rates for FAM reported in the medical literature varies substantially - from one percent to as high as twenty percent, given the failure to see intentional violation of the rules as "nonuse"; but the average reported is ten to twelve percent. Weschler, supra note 182Error! Bookmark not defined., app. d at 359. The Guttmacher testimony, then, either was not based on reputable medical literature or was based on clearly outlier data. Weschler explains that entities with financial ties to contraceptive use often distort the data. See id. at 7-8.

210. In the 1995 IOM publication, examined infra in Part III(D), the IOM Committee explains that the concept of "family planning" includes the "world of education, counseling, and care that supports careful contraceptive use." THE BEST INTENTIONS, supra note 191, at 12. In the medical and public health professions, contraception is commonly referred to as "family planning." Brief for American College of Obstetricians and Gynecologists as Amici Curiae Supporting Plaintiffs-Appellees at $30 \mathrm{n}$. 5, Standridge v. Union Pac. R.R. Co., 479 F. $3 d 936$ (8th Cir. 2006) (No. 06-1706), 2006 WL 6275678. 
by the American Congress of Obstetricians and Gynecologists (ACOG), literature produced under the umbrella of the Guttmacher Institute, and, most predominantly, the 1995 IOM publication. ${ }^{211}$ As explained in the following subsections, these sources do not focus on "strategies of family planning," but on an exaggerated view of the "problem of unintended pregnancy" and on a contraceptive-based solution lacking sound analytical support. ${ }^{212}$ The uncritical reliance justifies the dissenting member's point that the CPSW recommendations in the 2011 Report reflect subjective preferences and "determinations filtered through a lens of advocacy." The uncritical reliance perhaps was tied in part to a very short time frame in which to produce recommendations, but also very likely was tied to views of committee members solidified by an intensive campaign promoting contraceptive use, a campaign driven in large part by self-interested proponents such as the Guttmacher Institute, but also fueled and legitimized by the 1995 IOM publication on unintended pregnancy. ${ }^{213}$

\section{The ACOG Materials}

CPSW relied heavily on positions advocated by the American Congress of Obstetricians and Gynecologists (ACOG) - explicitly as to the safety of contraceptives, and implicitly as to the overall conclusion that contraceptives are needed to promote women's health. As pointed out by the dissenting member, ACOG guidelines would constitute but weak evidence for the CPSW conclusion. Study of key ACOG materials reveals reasons why this is so. CPSW cites to patient education materials through which ACOG very obviously promotes use of hormonal contraceptives, yet review of professional guidelines shows that ACOG's official position is simply that it is appropriate to prescribe contraceptives for women interested in using them.

To support its conclusion that side effects of contraceptives are considered "minimal," CPSW included a citation to three pamphlets issued by

211. For example, the CPSW report explains that the Preventive Services Task Force has not ad dressed prevention of unintended pregnancy, but that numerous professional associations and interest groups recommend the use of "family planning services;" and, further, that other IOM publications had identified unintended pregnancy as a health condition of women requiring attention and had recommended making contraceptives more available and accessible. Closing the Gaps, supra note 79, at 104 (citing the 1995 IOM publication on unintended pregnancy, and also IOM, Women's Health Research: Progress, Pitfalls, and Promise (Washington, D.C.: The National Academies Press, 2010)).

212. See discussion infra Part III(D)(2)-(3).

213. Contraceptives are immensely popular in large part because of intensive efforts to saturate the culture with the pro-contraceptive message. The Guttmacher Institute, for example, seems to exist primarily for this purpose. It is thus rather matter of fact that most persons support contraceptive use because of contraceptive rhetoric continuously pushed into the limelight by self-interested proponents. However, even more can be said about the IOM committee members: the IOM panel was comprised overwhelmingly of persons with records of being tied to or substantially supportive of organizations dependent on or fully supportive of a contraceptive-based approach to family planning, e.g., Planned Parenthood and the National Abortion Rights Action League. See infra note 282 (explaining that the organization Americans United for Life has detailed ties between several members of CPSW and Planned Parenthood and other openly pro-abortion organizations). 
ACOG. 214 The ACOG materials relied on by CPSW present information about risks and benefits of contraceptives, but only in a conclusory and biased fashion. The three ACOG pamphlets cited by CPSW are characterized by ACOG as "patient education" publications, ${ }^{215}$ and address (1) birth control pills, ${ }^{216}$ (2) other hormonal birth control options (implants, injections, rings, and patches), ${ }^{217}$ and (3) emergency contraception. ${ }^{218}$

The pamphlets present a great deal of information. For example, the pamphlet on birth control pills (the Pill Pamphlet) explains the types of pills available (combination pills containing estrogen and progestin, and progestin-only pills); the alternative ways the drugs work in the body, e.g., by preventing conception (by preventing ovulation or the uniting of sperm and egg), or by aborting a pregnancy (by rendering it unlikely that a fertilized egg can attach to the uterus); the various recommended regimens for taking the pills; and benefits other than preventing pregnancy associated with the pill (regulation of the menstrual cycle, e.g., keeping them regular, lighter, shorter, and less painful; control of acne; and the possibility of decreasing the risk of cancer of the uterus and ovary). ${ }^{219}$ The Pill Pamphlet emphasizes that birth control pills are "very effective." 220 But also outlines numerous factors that may hamper the effectiveness of the pill (missing days, failing to take the pill at the same time each day, vomiting or diarrhea, or ingestion of other drugs (e.g., antibiotics, seizure control drugs, HIV drugs)), and urges frequent use of back-up methods of contraceptives. 221

Additionally, the three pamphlets present information about risks and side effects. Regarding hormonal birth control pills, ACOG explains that the pill increases the risk of certain health conditions, and acknowledges that some of the complications can be serious: blood clots in the legs, heart attacks and stroke, gallbladder disease, and liver tumors. ${ }^{222}$ ACOG notes:

[S] ome women should not use combination birth control pills because their risks of complications are increased. For example, women older than

214. See Closing the Gaps, supra note 79, at 105, 107.

215. See, e.g., Am. Cong. Of Obstetricians And Gynecologists, Birth Control Pills (2011) [hereinafter THE PILL PAMPHLET].

216. See id.

217. See AM. CONG. OF OBSTETRICIANS AND GYNECOLOGISTS, Frequently Asked Questions Implants, Injections, Rings, and Patches: Hormonal Birth Control Options (June 2012), http://www.acog.org/ /media/For\%20Patients/faq159.pdf?dmc=1\&ts=20140403T1850583456 [hereinafter Hormonal Birth Control Options FAQ].

218. See AM. CONG. OF OBSTETRICIANS AND GYNECOLOGISTS, Frequently Asked Questions Emergency $\begin{array}{llll}\text { Contraception } & \text { (Oct. 2013), } & \text { http://www.acog.org/ /media/For\%20Pa- }\end{array}$ tients / faq114.pdf?dmc=1\&ts=20140403T1850092186 [hereinafter Emergency Contraception FAQ].

219. See THE PILl PAMPHLET, supra note 216.

220. Id. The pamphlet presents failure rates for typical and perfect use, $8 \%$ and $1 \%$ respectively; but leaves it to readers to surmise what the failure rate will be for their own use. See id. However, the pamphlet clearly endorses the view that, even with an $8 \%$ failure rate, the pill constitutes an "effective" means of birth control. See id.

221. Id.

222. Id. 
35 years who smoke or women who have multiple risk factors for cardiovascular disease should not use combined hormonal methods. Also women with certain medical conditions should discuss using combined hormonal methods with their health care providers. ${ }^{223}$

ACOG also indicates that smoking greatly increases the risk of heart attacks and stroke. 224

However, the ACOG materials include only minimal statistical information and focus instead on ACOG's conclusions. The clear and overarching message presented by ACOG is that, "[f]or most women, the risk of serious complications from using combined hormonal methods is small." 225 Additionally, ACOG characterizes the numerous "most common" side effects of birth control pills - headache, breast tenderness, nausea, irregular bleeding, missed periods, weight gain, anxiety or depression, excessive hair growth acne - as "minor." 226 ACOG's final note is: "For most women, the pill is a safe and effective way to prevent pregnancy. It is easy to use, convenient, and reversible. Talk with your health care provider if you are interested in using this birth control method." 227

The pamphlet on other hormonal birth control options uses virtually identical language to present the very serious health risks associated vaginal rings and patches which release both estrogen and progestin.228 Additional health risks associated with rings and patches are infections, discharge, headaches, and weight gain. ${ }^{229}$ Additional health risks also are associated with implants and injections which release progestin, namely ectopic pregnancy and loss in bone density, respectively, and increased risk of cardiovascular disease, ${ }^{230}$ as are additional side effects, such as irregular bleeding, weight gain, mood changes, headaches, depression, nervousness, dizziness, or fatigue. ${ }^{231}$ Nonetheless the message from ACOG regarding all of these other hormonal methods is simply that they are "effective," 232 and, regarding the options releasing both estrogen and progestin - and thus that pose greater risk for very serious health risks - the message is that for most women, "the risk of serious complications is small." 233 Emergency contraception is presented as having similar side effects, but ACOG states that it otherwise is safer to use - because the emergency pills are used for a much shorter period of

223. Id.

224. Id.

225. Id.

226. Id.

227. Id.

228. Hormonal Birth Control Options FAQ, supra note 218.

229. Id. at ${ }^{*} 4-5$.

230. Id.

231. Id.

232. Id. (stating that with the implant less than 1 out of 100 women will become pregnant, with the injections 3 out of 100 women will become pregnant, with the vaginal ring 8 out of 100 will become pregnant, and with the skin patch 8 out of 100 women will become pregnant).

233. See id. 
time than regular use of hormonal birth control. ${ }^{234}$ The ACOG pamphlets thus present ACOG's conclusions relating to use of contraceptives.

Of course, CPSW's methodology allowed the ACOG pamphlets to suffice as evidence supporting its recommendation. Recall that the CPSW methodology encompasses four categories of evidence, one of which includes existing professional guidelines. ACOG guidelines arguably are reflected in the ACOG pamphlets - albeit with an added promotional twist. ${ }^{235}$ The ACOG guidelines list unintended pregnancy as a disease or condition that can be treated with sterilization or hormonal contraceptives. ${ }^{236}$ The guidelines note that sterilization may be recommended as safe and effective for women who desire permanent contraception (noting a method failure rate of $1 \%)^{237}$ The same guidelines list many potential harms associated with surgical procedures. ${ }^{238}$ The guidelines for hormonal contraceptives on the one hand clarify that prescribing may be possible despite certain conditions, ${ }^{239}$ and advise caution when certain other conditions are present. ${ }^{240}$ The potential harms spelled out in the guidelines largely parallel the risks and side effects reported in the pamphlets.

But two problems arise in relation to CPSW's reliance on the ACOG materials. Foremost, the official ACOG position as to contraceptives is ambivalent. The ACOG guidelines expressly state that the purpose of the recommendations in the guidelines is merely to promote "appropriate use" of the

234. Emergency Contraceptive FAQ, supra note 219.

235. See AGENCY FOR HEALTHCARE RESEARCH AND QUALITY, http://www.guideline.gov/browse/by-organization.aspx?orgid=85 (last visited Apr. 3, 2014) for a list of available ACOG guidelines.

236. See AM. COLL. [sic] OF OBSTETRICIANS AND GYNECOLOGISTS, BENEFITS AND RISKS OF STERILIZATION 1 (2013) [hereinafter STERILIZATION GUIDELINE], available at http://www.guideline.gov/content.aspx?id=39431\&search=sterilization\#Section420; AM. COLL. [sic] OF OBSTETRICIANS AND GYNECOLOGISTS, USE OF HORMONAL CONTRACEPTION IN WOMEN WITH COEXISTING MEDICAL CONDITIONS 1 (2000) [hereinafter USE OF HORMONAL CONTRACEPTION GUIDELINE], available at http:/ / www.guideline.gov/content.aspx?id=10924. Several guidelines-e.g., for (i) sterilization, (ii) long-lasting reversible contraception, (iii) use of hormonal contraception, and (iv) emergency contraception-designate the targeted disease or condition as "unintended pregnancy." AM. CoLL. [sic] OF OBSTETRICIANS AND GYNECOLOGISTS, EMERGENCY CONTRACEPTION 1 (2005) [hereinafter EMERGENCY CONTRACEPTION GUIDELINE], available at http://www.guideline.gov/content.aspx?id=15718; AM. COLL. [sic] OF OBSTETRICIANS AND GYNECOLOGISTS, LONG-ACTING REVERSIBLE CONTRACEPTION: IMPLANTS AND INTRAUTERINE DEVICES 1 (2005) [hereinafter LONG-ACTING REVERSIBLE CONTRACEPTION GUIDELINE], available at http://www.guideline.gov/content.aspx?id=34114; STERILIZATION GUIDELINE, supra, at 1; USE OF HORMONAL CONTRACEPTION GUIDELINE, supra, at 1. As explained by the IOM Committee on Unintended Pregnancy, accreditation requirements for ob-gyn programs until 1996 left much discretion relating to curriculum to medical schools and, as a consequence, clinical experience during residency focused mostly on oral contraceptives and sterilization. See The Best Intentions, supra note 189 , at 146 .

237. See guideline titled "Sterilization", at *3 (benefits and risks of sterilization), accessible via http://guideline.gov/index.aspx.

238. Id. at *3.

239. See LONG-ACTING REVERSIBLE CONTRACEPTION GUIDELINE, supra note 237, at 3.

240. See USE OF HORMONAL CONTRACEPTION GUIDELINE, supra note 237, at 3 (pointing to women over age 35 who are smokers and women with a history of venous thromboembolism). 
various methods addressed. ${ }^{241}$ That is, the guidelines do not themselves anywhere recommend use of the methods. Rather, the guidelines exist to provide guidance in the event a woman is interested in using a method and a physician is willing to prescribe. The guidelines are thus evidence merely a willingness of ob-gyn members to prescribe FDA approved contraceptives to women interested in using them. Just as CPSW missed the mark by pointing to FDA approval as evidence that contraceptive use promotes women's health, the CPSW read too much into ACOG's position. The ACOG guidelines simply are not evidence that contraceptive use is needed to promote women's health.

The other problem is that the obvious promotional nature of the ACOG pamphlets undermines the argument that they support the CPSW recommendation and bolsters the argument that the recommendation rests on ideology rather than evidence. Undoubtedly, members of ACOG and other health care professionals who prescribe sterilization and hormonal contraceptives place value on women's health. Nonetheless, a wealth of evidence exists showing that other factors significantly affect the prescribing patterns of physicians - in particular financial conflicts of interests, especially those stemming from relationships with pharmaceutical manufacturers. ${ }^{242}$ Additionally, ACOG members undoubtedly also have been influenced by the campaign to promote contraceptive use inspired by the 1995 IOM publication. These influences are in fact apparent in the ACOG pamphlets. Several aspects of the ACOG patient education materials reveal an effort to steer patients towards use of contraceptive-based birth control methods - methods advocated by the 1995 IOM publication, and also methods that require physician services and prescriptions that in-turn yield benefits to physicians who provide the services or write the prescriptions. ${ }^{243}$ Like the CPSW in the IOM Report, the pamphlets virtually ignore safer and equally effective methods of family planning. ${ }^{244}$

241. See, e.g., id at 4. The guidelines have a section titled "Benefits/Harms of Implementing the Guideline Recommendation." See, e.g., id. As a "potential benefit," ACOG lists "appropriate use" or "safe and effective use." See, e.g., id.; STERILIZATION GUIDELINE, supra note 238, at 4.

242. See, e.g., Christopher Robertson, Susannah Rose \& Aaron S. Kesselheim, Effect of Financial Relationships on the Behaviors of Health Care Professionals: A Review of the Evidence, 40 J. L. MED. \& ETHICS 452 (2012) (finding evidence that financial relationships bias physician decisions to different degrees in all three areas explored: the payments to referrers, the incentives created by health insurers, and the largesse provided by the drug and device industries).

243. An analysis on file with the author identifies the following indicators of bias: promoting the pill as easy and convenient when even IOM materials repeatedly acknowledge the difficulty associated with using contraception; omission of information about comparably effective and safer options of family planning; omission of key statistical information about serious risks; discounting serious health risks because pregnancy itself entails risks, without acknowledging that many women would approach the issue differently due to the benefits associated with pregnancy.

244. The ACOG pamphlets discussed supra did not discuss FAM, presumably because the purpose was to educate about options within the category of hormonal drugs and sterilization. Another pamphlet, however, illustrates a more deliberate decision by ACOG to ignore FAM, namely, a pamphlet for teens that purportedly presents information on the options available for avoiding pregnancy. See Am. CONG. OF OBSTETRICIANS AND GYNECOLOGISTS, Frequently Asked Questions Especially 
The ACOG guidelines thus provide little support for CPSW's recommendation that contraceptives be included in the mandate. The ACOG position represents merely a willingness of ACOG members to prescribe FDA approved hormonal contraceptives; a willingness to prescribe very likely influenced by factors other than the genuine health and well-being of women. At most the guidelines reflect ACOG's reliance on FDA findings of safety and efficacy and thus fail to constitute evidence that contraceptives genuinely promote health and are not merely popular services. CPSW's reliance on the ACOG materials was thus uncritical and evidence that its analysis was influenced by ideology.

\section{D) The 1995 IOM Publication on Unintended Pregnancy}

The other publication heavily relied on by CPSW was the 1995 IOM publication on unintended pregnancy. Titled The Best Intentions: Unintended Pregnancy and the Well-Being of Children and Families (The Best Intentions), the publication fueled an intensive campaign promoting contraceptive use in the United States; a campaign that has resulted in family planning being equated with contraception to the exclusion of other feasible, effective, and safe methods. ${ }^{245}$ However, scrutiny of The Best Intentions reveals omission of any consideration of health risks, an overly expansive approach to "the problem,"

for Teens Birth Control (Dec. 2013), http://www.acog.org/ / media/For\%20Patients/faq112.pdf?dmc=1\&ts=20130117T1639391035.

The pamphlet answers the question "Which birth control methods are the best at preventing pregnancy?" with information about "all of the birth control methods and how well they protect against pregnancy." Id. The methods presented are: Implant, IUD, sterilization (less than 1 pregnancy per 100 women); Injection, pill, patch, vaginal ring (6-9 pregnancies per 100 women); Male condom, cervical cap, sponge, diaphragm, female condom (12-24 pregnancies per 100 women); and Spermicides ( 28 pregnancies per 100 women). Id. The pamphlet also provides a very brief description of each of these methods. See id. Notably, this pamphlet does not include any information about health risks or side effects associated with these birth control methods. See id. Indeed, health risks and side effects are not even listed as items to consider when choosing a birth control method. Id. The pamphlet explains: "To choose the right birth control method, consider the following: How well it prevents pregnancy; How easy it is to use; Whether you need a prescription to get it; Whether it protects against sexually transmitted diseases (STDs); [and] Whether you have any health problems." Id.

Moreover, the pamphlet mentions fertility awareness-based methods only in fine print in a footnote, with instructions to discuss these options with a health care provider. Id. Yet, as explained, the most accurate fertility awareness method when properly used is comparably effective with perfect use of hormonal birth control options - even those options characterized as "more effective" than the pill, such as implants, injections, vaginal rings and patches. Thus, ACOG clearly is steering teens toward contraceptive-based methods of family planning that render them dependent on pharmaceutical manufacturers and health care providers for family planning.

245. The campaign has been aided greatly by the work of the Guttmacher Institute. The agenda of the Guttmacher Institute is well known. The Guttmacher Institute was founded in 1968 as the Center for Family Planning Program Development, a semi-autonomous division of The Planned Parenthood Federation of America. About the Institute: The History of the Guttmacher Institute, GUTTMACHER INST., http://www.guttmacher.org/about/history.html (last visited Apr. 4, 2014). It was founded by then Planned Parenthood President, Alan F. Guttmacher. Id. The Institute was later named after him. Id. The Institute reorganized as a separate entity in 1977. Id. As recently as 2010 though, Planned Parenthood provided $\$ 78,000$ to the Guttmacher Institute. About the Institute: Frequently Asked Questions, GUTTMACHER INST., http://www.guttmacher.org/about/faq.html (last visited Apr. 4, 2014). The Institute's overarching goal is to "ensure the highest standard of sexual and 
exaggerated consequences, and imprecise identification of causation which in-turn prevents identification of genuinely effective remedies. These analytical shortcomings also provide evidence of the pre-ordained perspective of CPSW and further support the dissenting member's critique of the CPSW report.

\section{1) Omission of Consideration of Serious Health Risks}

The most obvious shortcoming of the publication is the failure to provide any assessment of health risks associated with contraceptive use. In The Best Intentions, an IOM committee - the Committee on Unintended Pregnancy (the Committee) - advocates for a radical change in social norms in the United States that hinges on a massive multi-pronged campaign to promote regular and long-term use of contraceptives by all virtually women of reproductive age. The publication is fairly massive: 272 pages (with an additional 92 pages of appendices). The publication points to various findings purportedly supporting its conclusion that "the consequences of unintended pregnancy are serious, imposing appreciable burdens on children, women, men, and families." 246 Some of those burdens are health related, and those parallel the health concerns cited by CPSW and HHS, confirming that both CPSW and HHS looked to this IOM report. The publication also details findings relating to patterns of contraceptive use, knowledge and access to contraceptives, the many factors bearing on use of contraceptives, and programs designed to reduce unintended pregnancy. ${ }^{247}$ Yet, despite this fairly comprehensive discussion of contraception and the Committee's overarching advocacy for a campaign to promote regular and long-term use of contraceptives by virtually women of reproductive age, the publication contains no explicit discussion of the health risks. Rather, the publication only hints at the risks in a backhanded way. The Committee stated:

There is . . clear evidence that many Americans are misinformed about the risks and benefits of particular contraceptive methods - exaggerating the former and underestimating the latter, especially in the case of oral contraceptives. For example, a 1993 Gallup poll found that more than half of American women believe there are "substantial risks" (mainly cancer) involved in using the birth control pill, and 4 in 10 erroneously believe that the health risks of taking oral contraceptives are greater than those of childbearing. ...

reproductive health for all people worldwide." About the Institute: Mission, Values, and Guiding Principles, GUTTMACHER INST., http://www.guttmacher.org/about/mission.html (last visited Apr. 4, 2014). Information about the Guttmacher Institute is accessible at http://www.guttmacher.org. It is well known that the phrases "sexual health" and "reproductive health" are generally used to promote rights to abortion and contraception services. The information and data provided by the Guttmacher Institute are often used by persons and entities opposed to abortion and the promotion of contraceptive-based approaches to family planning, but, nonetheless, a review of the non-stop stream of papers, reports, and other publications associated with the Guttmacher Institute clearly reveals its biased agenda.

246. The Best Intentions, supra note 202 , at 1 .

247. See id. at 91-249. 
Numerous smaller studies confirm this general picture... [ [For example, in a study conducted in 1991,] 247 women (mean age of 30.2 years) receiving care at a university health center were queried about their views of the benefits and risks of the pill. Almost half believed that oral contraceptives carry substantial risks, cancer in particular. ${ }^{248}$

The publication identifies clear examples of misinformation-e.g., ideas that an IUD can "get lost in the body" 249 - and findings relating to lack of knowledge of anatomy, physiology, and fertility generally. ${ }^{250}$ The Committee concludes that "[s]uch misinformation can lead to poor contraceptive use and therefore unintended pregnancy." 251 However, the Committee nowhere in the publication provides evidence of findings that show that women's concerns about the health risks associated with contraceptives, and the pill in particular, are properly characterized as "misinformation."

The absence of any attention to health risks in the 1995 IOM publication, coupled with CPSW's failure to address health risks in the 2011 IOM Report, is evidence of uncritical reliance by CPSW on its sources. The validity of this assertion is supported by the recently published peer-reviewed research highlighting serious health risks associated with use of hormonal contraceptives. As noted supra, this research should have made very clear the genuine need for the rigorous risk/benefit assessment expected by (or purportedly expected by) HHS. CPSW's failure to address in 2011 the known serious health risks is explicable only in reference to an existing and unstated assumption. An assumption grounded in FDA approval for marketing and in ACOG's conclusions regarding contraceptives (that they are "sufficiently effective" and, further, that risks are "small and minor"), ${ }^{252}$ and fueled by the campaign to promote cultural acceptance of the importance of use of contraceptives.

The Best Intentions has other significant shortcomings as well, rendering it problematic that HHS and CPSW relied on this work to support the contraceptive mandate. According to the methodology set out by CPSW, its recommendation regarding contraceptives would need to be supported by "sufficient evidence" that contraception decreases the likelihood or delays the onset of unintended pregnancy. ${ }^{253}$ The position or conclusion advocated in The Best Intentions would support CPSW's recommendation, but the case is flawed. As noted, the Committee in The Best Intentions advocates for a massive multi-pronged campaign to promote regular and long-term use of contraceptives by all virtually women of reproductive age. The purpose of the campaign is to promote the Committee's one overarching recommendation: "All pregnancies should be intended - that is, they should be consciously and

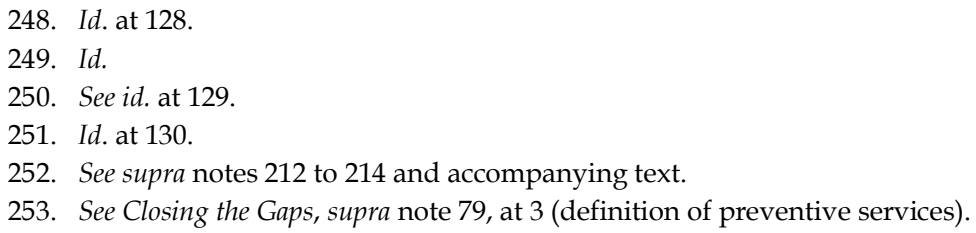


clearly desired at the time of conception."254 The key evidence supporting that recommendation is an artificial concept - the construct referred to as "unintended pregnancy." The Committee's recommendations flow from its expansive definition of "unintended pregnancy" and its imprecise view of the cause of and consequences flowing from this constructed concept. ${ }^{255}$ There is some internal logic to the Committee's approach, but, when scrutinized from the perspective of women's health, key flaws emerge.

\section{2) The Artificial Construct of "Unintended Pregnancy" Overstates the Problem}

The importance of family planning to women's health is grounded in discrete health concerns related to pregnancy and childbirth (e.g., unhealthy behaviors before and during pregnancy, pregnancies occurring too close together, or pregnancies in certain at-risk populations). ${ }^{256}$ The 1995 IOM Committee purports to address these health concerns, but its approach leads to an unnecessarily expansive and intrusive strategy. The Committee targeted "unintended pregnancy" as a problem and defined "unintended pregnancy" as including any pregnancy that was either unwanted or mistimed at the time of conception. ${ }^{257}$ This approach captures every pregnancy other than one resulting from a conception consciously wanted at the time of conception or sooner. That is, the approach includes all mistimed conceptions despite the fact that many women (and couples) do in fact want the child either from the time of learning of the conception and pregnancy, or by the time of the birth. Moreover, the approach also captures the many pregnancies experienced by women (and couples) who are open to having a child, but who have not formed a specific intent and thus are not affirmatively seeking to get pregnant at the time of the conception. The Committee has thus defined "the problem" so broadly that, as discussed infra, an approach to family planning that many women and couples embrace and that historically has proven to be associated with healthy pregnancies and healthy children becomes part of "the problem."

The Committee's approach constitutes a leap in logic. Certain discrete health concerns support the idea that planning for pregnancy safeguards the health of women and children. But that does not logically mean that any pregnancy that is not intended - not consciously and clearly intended at the

254. The Best Intentions, supra note 202 , at 3 .

255. As noted, CPSW cited goal of the Committee on Unintended Pregnancy that "all pregnancies should be intended" as support for recommendation 5.5. See Closing the Gaps, supra note 79, at 104. Unintended pregnancy is defined in the report as an unwanted or mistimed pregnancy at the time of conception. Id. at 102 (citing Finer and Hinshaw, Disparities in rates of unintended pregnancy in the US, in 1994 and 2001, in Perspectives on Sexual and Reproductive Health, 38(2):90-96 (2006)). Hinshaw is associated with the Guttmacher Institute. See supra note 140.

256. See, e.g., supra note 154 .

257. The Best Intentions, supra note 202, at 22 . This also was the definition used by CPSW - relying on the work of researchers associated with the Guttmacher Institute. See supra notes 139 to 141 and accompanying text. 
time of conception - contributes to poor health outcomes. Many pregnancies falling within the Committee's definition of the problem are experienced by women and couples who are willing and able to act responsibly and thereby are able to avoid poor health outcomes.

The Committee acknowledged the complexities involved in attaining good data as to unintended pregnancies, but does not provide a clear explanation for why it took such a broad approach. This is puzzling since the report also clarifies that the potential negative consequences (especially the potential health problems) are much less when a pregnancy is merely mistimed - i.e., when a conception occurs that is wanted, but which has occurred sooner than the woman has "intentionally wanted"; and less also when, although the conception may not have been wanted at the time, the child is nonetheless welcomed and cherished. ${ }^{258}$ The Committee identified several factors prompting their study of unintended pregnancy: higher rates of "unintended pregnancies" in the United States, in relation to several other industrialized countries; the "marginalization" of family planning (by whom is not clear), and failure to integrate it with discussions relating to children's wellbeing; health reform policy discussions raising issues as to coverage of contraception; the rise in birth rates for teens and unmarried women, especially unmarried white women; and welfare reform policy discussions identifying welfare as an incentive to pregnancy and seeing pregnancies as disrupting job training and educational programs for mothers on welfare. ${ }^{259}$ Only the last reason might point to the need to capture all pregnancies and conceptions but those consciously and clearly intended at the time of conception.

Importantly, however, the publication is marketed as being relevant primarily to health goals rather than to welfare goals. And, indeed, reliance on this publication by CPSW and HHS was for the purpose of health goals rather than welfare goals. Because the Committee acknowledged that potential health concerns are much less significant when a pregnancy is merely mistimed, the Committee's approach to "the problem" clearly is overbroad for purposes of developing sound health policy.

Of course the Committee's decision to focus on unintended pregnancy, broadly defined, dramatically increases the scope of the purported problem. That is, defined as it is, the risk factors necessarily are broad. The Committee defined women at risk as those who (1) have had sexual intercourse, (2) are fertile, and (3) are neither intentionally pregnant nor have they been trying to become pregnant during any part of the year. ${ }^{260}$ According to the Committee, in 1990 this encompassed about half of the 62 million women between

258. The Best Intentions, supra note 202, at 21-23.

259. Id. at 11-16. Other factors included controversies over content of sex-education programs and access to abortion; failure to involve men in family planning services; increased child support enforcement that provides incentives for men to take responsibility for preventing unintended pregnancies; and, increasing incidence of HIV infection among women. Id.

260. Id. at 28 . 
ages $13-44,261$ and, thus, defined in this way, "the problem" can be characterized as frequent and widespread - a characterization essential for CPSW's methodology to encompass contraceptives and sterilization. ${ }^{262}$

Defining the problem broadly as unintended pregnancy similarly allows a very broad approach to identifying consequences or burdens. The Committee pointed to burdens on women, men, children, families, and society. The burdens the Committee highlighted include the potential that prenatal care is delayed or that a pregnant woman may not alter harmful behaviors (use of tobacco or alcohol), and risks relating to educational and career goals of the mother or father. Burdens associated with an unwanted pregnancy (and not merely a mistimed one) include risks to the child (greater risk of being aborted, or of low birth weight, infant death in the first year, child abuse, or of not receiving sufficient resources for healthy development) and risks to the mother (greater risk of depression or instability in relationships, including abuse). ${ }^{263}$ Many of these burdens are not health related concerns, however, and many listed health concerns are much less probable when the pregnancy is merely mistimed. ${ }^{264}$ Further, as highlighted by the BCPI brief, as to the link between the "burdens" and "unintended pregnancy," scientific evidence of causation is simply lacking. Thus, again, using this artificially broad approach for purposes of health policy is unnecessary and unhelpful. The subset of pregnancies genuinely posing serious health concerns is considerably smaller, and capturing them within a category unnecessarily expansive interferes with identifying focused remedies. The unnecessarily expansive approach also raises questions as to whether the 1995 IOM Committee manufactured the concept in an effort to justify the proposed solution - a solution that would require an intensive campaign to radically change social norms

261. Id.

262. Without this exaggerated approach, the "target condition" does not clearly have a "large potential impact on health that affects a broad population."

263. The Best Intentions, supra note 202, at 1 ; see also id. (chapter 3).

264. Another difficulty with the Committee's approach - a difficulty not addressed by the Committee - is that the prevalence of many of the identified burdens has actually increased as contraceptive use in society has increased. See, e.g., The Gift of Female Fertility, supra note 184, at 108-110. Franks explains that, from the outset, contraception was touted as the answer to a host of wide-ranging societal problems, including overpopulation, marital unhappiness, and child abuse. She also explains that statistics contradict such claims, pointing to, e.g., demographers who attribute half of the rise in the divorce between 1965 and when it leveled off in 1976 to the "unexpected nature of the contraceptive revolution"; the significant increase in the rate of unwed motherhood and child abandonment by fathers; and the staggering increase in the number of abused children. She also notes that statistics do not support the oft repeated claim that contraceptives prevent abortions.

Indeed, the statistics in The Best Intentions contradict the Committee's version of this assertion. The Committee acknowledged that over half of untended pregnancies are experienced by woman who use contraceptives, and that the most important factor bearing on whether an unintended pregnancy is aborted is whether the woman is married. See The Best Intentions, supra note 202, at 41-42. The statistics thus point clearly to the fact that contraceptive use by unmarried women does not prevent abortions. Frank explains: "[The reality is] that contraception closes the partners' hearts, here and now to a child. No thought goes into what might happen if a child is conceived. So, when a child comes - as one so often does, given the fact that sex tends to produce what it is meant to produce - the adults are not mentally open to her. They have contracepted their hearts." The Gift of Female Fertility, supra note 184, at 109. 
in the United States. Alone, the Committee's unduly expansive approach renders reliance by CPSW and HHS on the 1995 IOM publication problematic. But, other shortcomings exist.

\section{3) The Advocated Goal and Strategy Rest on Questionable Logic}

Seeing the problem in terms of the overly broad construct of unintended pregnancy also was integral to the goal articulated and the strategy advocated by the Committee. The Committee's overarching stated goal was as follows: "All pregnancies should be intended - that is, they should be consciously and clearly desired at the time of conception." 265 The strategy for attaining the goal is to promote knowledge of and access to contraceptives, with the practical consequence of regular and long-term use of contraceptives by virtually all women of reproductive age. Again, there is some internal logic to the Committee's approach. Unintended pregnancy is the problem. Unintended pregnancy causes burdens. All pregnancies thus should be intended. For the reasons already explored, this goal is unnecessarily overexpansive. The solution also is flawed. The Committee identifies as the cause of unintended pregnancies "sexual activity accompanied by contraceptive misuse, failure, or nonuse altogether."266 The solution therefore is that women and couples should be inculcated such that sexual activity always is accompanied by proper contraceptive use - unless there is a clear and specific desire to have a child. For several reasons the goal and strategy are not logical from the perspective of health policy.

Foremost, the goal is unattainable given the strategy advocated. The strategy advocated by the Committee is more and better use of contraceptives. The Committee advocates for a campaign that would improve knowledge about and access to contraception, ${ }^{267}$ promote use of longer-lasting hormonal contraceptives (e.g., implants, injectables, and IUDs); ${ }^{268}$ encourage local programs aimed at molding individual and community values, and the culture, to support increased use of contraception; ${ }^{269}$ and stimulate research to develop new methods, enhance access to prescription services, and understand more fully the factors affecting contraceptive use. ${ }^{270}$ Yet, at the same time the Committee acknowledged that reliance on contraceptives always involves failures. Indeed, the Committee noted that, currently, "most women not actively seeking pregnancy use contraceptives" - i.e., most women who, given the Committee's definition, are at risk of unintended pregnancy in fact do use contraceptives. The problem is that pregnancies still occur.

\footnotetext{
265. The Best Intentions, supra note 202 , at 3 .

266. Id. at 91 .

267. Id. at 56 .

268. Id. at 6,8 .

269. Id. at 9 .

270. Id. at 10 .
} 
The problem ... is that even if most people use contraception most of the time, and even if access to the best methods of contraception is more or less adequate in most places, the net result will be an appreciable level of unintended pregnancy, given the relative ease with which pregnancy occurs. ${ }^{271}$

It is for this reason that the Committee advocates resort to longer-lasting hormonal methods such as implants, injectables, and IUDs - devices over which women have no control once in place. ${ }^{272}$ Importantly, however, the Committee also explained the statistical reality associated with use of typical contraceptive methods - including all hormonal methods.

It is important to emphasize that, given the imperfect array of contraceptives available ... and the years of exposure to the risk of unintended pregnancy, some appreciable number of unintended pregnancies will inevitably occur over the life course. One simple computation suggests that this accumulates to a large risk over time. [Consider] the example of a young couple of undiminished fertility who use a contraceptive that is 95 percent effective. In this example, the couple experiences a monthly risk of pregnancy of about 1 percent. Over 10 years, that risk accumulates to a 70 percent probability that an unintended pregnancy will occur at some point during the decade. [Other researchers] have estimated that the average woman will experience one contraceptive failure for every 2.25 live births, a number that increases substantially if women [whose partners are sterilized] are excluded from the analysis. These data underscore the fact that an appreciable part of both a woman's and a man's reproductive life span is spent at risk of unintended pregnancy, using a variety of reversible contraceptive methods that are rarely, if ever, 100 percent effective. ${ }^{273}$

The Committee's approach thus is not logical. The Committee is advocating for a strategy that would require regular and long-term use of contraceptives by virtually all women of reproductive age and, yet, the Committee's stated goal that "all pregnancies be intended" is simply unrealistic with a contraceptive-based strategy. From a biological perspective, pregnancy is the natural and intended consequence of sexual activity between a man and woman. Use of contraceptives involves manipulation of the human reproductive system, or sexual activity itself, to thwart the natural and intended consequence. A contraceptive-based strategy encourages women and couples who do not desire (or intend) the consequence (conception and pregnancy) to nonetheless engage in the human activity that, from a biological perspective, is intended to result in that consequence - and to do so in reliance on drugs and devices that are known to always be subject to a very real risk of failure, a risk that, in reality, is quite large. ${ }^{274}$

Additionally, the strategy itself is flawed. The strategy of inculcating

271. Id. at 138 .

272. Id. at 8 .

273. Id. at $101-102$.

274. The Committee expressly endorsed as "realistic" HHS's goal that unintended pregnancies be reduced to 30 percent of all pregnancies by the year 2000. Id. at 3 . 
women and couples such that sexual activity always is accompanied by proper contraceptive use is unattainable for a number of reasons. First, use of FDA approved contraceptives (and even many over-the-counter contraceptives) requires skill sets and discipline that render "always perfect use" extremely unlikely. For example, several well-known difficulties are associated with using the condom properly. ${ }^{275}$ Challenges associated with use of the pill are less well known. Indeed, the popularity of the pill supposedly is related to its ease of use. But, the Committee itself in The Best Intentions repeatedly alludes to the difficulty associated with using contraception, and explains:

There is also no doubt that using many of the reversible contraceptive methods correctly and consistently can be very challenging. For example, [a 1994 study] sketched the chain of events that using oral contraceptives requires a woman to master: obtaining pills, taking them in the correct order, taking each pill within the appropriate time window, abstaining from sex or using a backup method when necessary, obtaining refills on time, stopping one cycle and starting the next at the right time, interpreting problems correctly (neither overreacting nor under-reacting), and taking effective action to resolve problems. ${ }^{276}$

The Committee concludes: "There is no doubt that using many of the reversible contraceptive methods correctly and consistently can be very challenging." 277 Thus, the strategy is unattainable - unless women in ever-larger numbers are persuaded to regularly use the more dangerous long-lasting hormonal options.

But this in-turn also is not likely to happen because many women and couples who use contraception often elect to not use them because they do not like them. ${ }^{278}$ Many reasons exist for being dissatisfied with contraceptives. The most frequently used methods - the pill and sterilization - involve mutilation or distortion of healthy reproductive systems. All hormonal contraceptives pose serious health risks stemming from the ingestion of drugs (e.g., blood clots, heart attacks and stroke, ectopic pregnancy, loss in bone

275. See, e.g., Stephanie A. Sanders et al., Condom use errors and problems: a global view, 9 Sexual Health 81-95 (2012) (involving a systematic literature search conducted for peer-reviewed articles, published in English-language journals between 1995 and 2011; fifty articles representing 14 countries met criteria for inclusion; the most common errors included not using condoms throughout sex, not leaving space at the tip, not squeezing air from the tip, putting the condom on upside down, not using water-based lubricants and incorrect withdrawal; frequent problems included breakage, slippage, leakage, condom-associated erection problems, and difficulties with fit and feel; prevalence estimates showed great variation across studies, and prevalence varied as a function of the population studied and the period assessed; conclusion: condom use errors and problems are common worldwide, occurring across a wide spectrum of populations). Sanders is associated with The Kinsey Institute for Research in Sex, Gender, and Reproduction, The Department of Gender Studies, and the Rural Center for AIDS/STD Prevention at Indiana University, Bloomington.

276. The Best Intentions, supra note 202, 100-101.

277. Id. at 100-101.

278. Id. at 171 (noting, "one reason women often give for not using contraceptives is that they are concerned about the side effects or health risks of contraception in general and of specific methods in particular") (citing studies). See also Guttmacher Institute, In Brief: Improving Contraceptive Use in the United States (2008 Series, no. 1), 4-5. 
density, gall bladder disease and liver tumors - and breast cancer), and unpleasant side effects (e.g., headache, breast tenderness, nausea, irregular bleeding, missed periods, weight gain, anxiety or depression, excessive hair growth, acne). ${ }^{279}$ Side effects of an IUD placed in a woman's uterus include menstrual pain and heavy bleeding. ${ }^{280}$ Couples also dislike contraceptives such a condoms or spermicides that complicate and introduce variables that interfere with or are noticeable during sexual activity. ${ }^{281}$ This very real and known dissatisfaction with contraceptive methods cuts against the Committee's strategy itself and, as well, undermines the Committee's attempt to bolster its strategy by emphasizing the importance of educating and inculcating individuals and communities to achieve the goal. Information and education cannot change the fact that women and couples do not like to use contraceptives.

More fundamentally, sexual activity will not always be accompanied by contraceptive use because the strategy is inconsistent with the family planning strategy used and embraced by many women and couples in the United States. In essence, given the Committee's definition of unintended pregnancy, the Committee's goal would require use of contraceptives anytime a couple engages in sexual activity without consciously and clearly wanting child at that time. For many married couples, this strategy would be flatly inconsistent with their views about being open to children.

For example, although an attitude of being open to children is held by many, the attitude is an especially important aspect of Judeo-Christian values. Holy Scripture teaches that God's plan for humanity includes humans using the gift of sexuality for its intended purpose - namely, as a means to participate in God's saving plan and respond to his call to grow in holiness. ${ }^{282}$ More specifically, the Christian faith teaches that the sexual act - or marital act - is a means to achieve the twofold ends of marriage: the good of the spouses and the transmission of life. The marital act fosters mutual love and fidelity. It also allows a couple to share in the creative power of God: "In giving birth to children and educating and forming them, they cooperate in the love of God as Creator."283 Most Christian denominations urge couples to be open to children. ${ }^{284}$ The teaching of the Catholic Church goes further

279. See supra notes $157-178,202-221$ and accompanying text.

280. See ACOG, Frequently Asked Questions (FAQ014), Contraception: Intrauterine Device (January 2012), at ${ }^{2} 2$, accessible at http://www.acog.org/ /media/For\%20Patients $/$ faq014.pdf?dmc=1\&ts=20130117T1713425878.

281. See, e.g., Guttmacher Institute, In Brief: Improving Contraceptive Use in the United States (2008 Series, no. 1), 5 (noting that barrier method users report being dissatisfied with available options, and that providers rank as the most common "problem" among contraceptive clients the fact that women skip use of a barrier method because it is unavailable or they find it too inconvenient).

282. The idea that a key purpose of the sexual union between a man and woman is the procreation of children has its origin in the Book of Genesis, and more specifically in the directive to man and woman to "be fruitful and multiply." See Genesis 1:28.

283. See, e.g., Catechism of the Catholic Church (2d ed.) (Double-day: New York, 1995), § 409

284. All Christian denominations condemned contraception before 1930. In 1930 at the Lambeth Conference the Anglican Church decided to allow a limited exception for use by husband and wife. 
by pointing to an inseparable link between the unitive and procreative aspects of marriage. Contraception in fact separates these two aspects of relationship and, for this reason, is considered contrary to God's plan for human love. ${ }^{285}$ For practicing Catholics, although responsible spacing of children is appropriate, each and every sexual act in a marriage must to be open to the possibility of conceiving a child. ${ }^{286}$ For non-Catholic Christians and others who adhere to aspects of Judeo-Christian faith, many and perhaps most acts of sexual intercourse should be open to the possibility of conceiving a child. The Committee's strategy, then, not only is inconsistent with traditional and popular approaches to family planning, but also - especially to the extent the Committee advocates for government endorsement and support in various ways - opens the door to infringement on religious beliefs and practices.

In The Best Intentions, the Committee recognized the radical nature of its recommendation. The Committee stated: "The committee has concluded that reducing unintended pregnancy will require a new national understanding about this problem and a new national consensus that pregnancy should be undertaken only with clear intent. Accordingly, the committee urges, first and foremost, that the nation adopt a new social norm." 287 The committee's secondary recommendation similarly reveals the radical nature of the goal: "To begin the long process of building national consensus around this norm, the committee recommends a multifaceted, long-term campaign to (1) educate the public about the major social and public health burdens of unintended pregnancy and (2) stimulate a comprehensive set of activities at national, state, and local levels to reduce such pregnancies."288 Government officials have been on-board with this campaign for decades and, in issuing the contraceptive mandate, HHS has, in essence, continued governmental endorsement of this heavy-handed approach to fostering contraceptive use.

Of course, the BCPI brief highlights the fact that statistical evidence

Within a few decades, most Protestant denominations followed suit and the scope of the exception grew. See Franks, The Gift of Female Fertility, supra note 184, at 97.

285. See, e.g., Catechism of the Catholic Church, $\$ 409$. The Church recognizes that serious reasons may exist that cause a couple, at particular points in time throughout a marriage, to not want to conceive a child. It is not morally illicit for a married couple to use fertility awareness methods to enable them to avoid a pregnancy by abstaining from the marital act during the woman's fertile period. There is a vast difference, however, between choosing to not use sexuality at some times during a marriage, and choosing to use contraceptives so that the couple can use the gift of sexuality without being open to children.

286. Use of FAM is consistent with the Catholic faith. Id. See also Franks, The Gift of Female Fertility, supra note 184, 110-17 (explaining that discernment of responsible parenthood is "an interior openness" to God's generous, life-giving will; that contraception works against human happiness by elevating immediate self-gratification to the position of primacy in sexual decision-making; that FAM is distinguishable because it involves a decision to refrain from action rather than a decision to act in a way that would offend God couple; and noting: "When the procreative end of sex is deliberately thwarted through contraception, the ability of the spouses to unite in total self-give (the unitive meaning) is thwarted as well.").

287. The Best Intentions, supra note 202 , at 3 .

288. Id. at 4 . 
shows that decades of governmental promotion of low or no-cost contraception and emergency contraception have failed to reduce unintended pregnancies: i.e., the current rate of unintended pregnancy reflects a 40 percent increase since 1972 (despite "multiple programs and policies operating on the same premise as the HHS mandate"). ${ }^{289}$ That failure demonstrates the flawed nature of the goal and strategy set out in The Best Intentions.

Notably, the Committee's decision to advocate for contraceptive use hinged on its view of the "cause" of the problem of unintended pregnancy a view that also suffers from flaws. The Committee stated: "The direct cause of unintended pregnancy, of course, is sexual activity accompanied by contraceptive misuse, failure, or nonuse altogether." 290 This statement is imprecise. The "cause" of conception and pregnancy is engaging in sexual activity during the period of time near when a woman ovulates; and, more particularly given the Committee's definition of unintended pregnancy, engaging in such activity without consciously intending a child at the time. Again, the Committee's view that this always is a "problem" is overbroad because many women and couples nonetheless welcome a conception or pregnancy that results from the activity and the burdens purportedly associated with the pregnancy are thus greatly mitigated. But, for some women and couples, a resulting unintended pregnancy could present burdens - some of which may be health related. More precise identification of the "cause," however, would point to a more precise and effective solution.

If the cause is engaging in sexual activity during the period of time near when a women ovulates (the fertile period) without consciously wanting a child at the time, the more precise and effective solution is to refrain from sexual activity during the time period when the conditions exist that make conception a real possibility. Contraception fails because the human reproductive system is amazingly efficient at achieving its biological function. Rather than working against the biological efficiencies of the human reproductive system, a more logical and sensible approach would be to respect and work with that system. A more logical solution than the contraceptive strategy pushed by the Committee thus would be to promote use of FAM.

As discussed supra, FAM provides a method of family planning that is equally effective without imposing on women the serious health risks associated with hormonal contraceptives. A FAM-based strategy also is feasible - from both a biological and practical perspective. ${ }^{291}$ In addition to its proven

289. BCPI Brief, supra note 79, at 9-11.

290. The Best Intentions, supra note 202, at 91.

291. As discussed, proper use of FAM is feasible, highly effective, and safe. Scientifically proven reliable physical signs readily can be detected that allow women and couples to identify the time period near when ovulation is likely to occur. FAM also is a realistic option for family planningespecially for those persons most likely to be adversely affected by an undesired pregnancy, namely, women and couples with actual motivation to avoid pregnancy - because the time period when conception is a real possibility is finite, delimited, and identifiable (at least when the system has not been disrupted by an infusion of artificial hormones). FAM as a tool for family planning also is realistically attainable from the perspective of skills: the skill set required for effective use of FAM is much less sophisticated than that required for effective use of current mainstream contraceptives. The IOM 
effectiveness and safety, FAM is consistent with the family planning method currently embraced by many in the United States, and historically associated with healthy pregnancies and healthy infants. As such, success does not hinge on a multi-faceted, intensive campaign to "prompt the nation to adopt a new social norm" and to inculcate women and couples to accept and use undesirable contraceptives on a regular and long-term basis - contraceptives they do not like. FAM allows couples to plan for pregnancies, but also enables couples to engage in sexual activity without the health risks, side effects, or undesirable variables and complications associated with contraceptives. Because FAM does not require ingestion of drugs or use of devices, women and couples who consciously do not want a child will have fewer reasons to abandon it.

Moreover, a FAM-based strategy would better serve the health concerns underlying the importance of family planning, namely, failures to be in good health prior to pregnancy, delays or refusals to seek prenatal care, refusals to forego risky activities during pregnancy, such as alcohol or drug use, etc. These irresponsible behaviors are the real contributing factors to poor maternal and infant health outcomes. Effective family planning is thus best understood as activities that help ensure women are healthy when they conceive and sufficiently responsible (i) to be alert to the possibility of conception if they are sexually active, and (ii) to maintain a healthy lifestyle and access available prenatal care during a pregnancy; and would include activities that help ensure that women delay conception and pregnancy until they are sufficiently responsible to do the things that foster good health outcomes. Contraceptive use does not foster the type of responsible attitude critical for effective family planning. Contraception provides a means of family planning whereby couples feel free to engage in sexual activity despite having a desire to not have a child - and often without concern about whether a woman or the couple is willing and able to care for a child - and, further, to do so at any time and without thinking about the normal biological purpose or operation of the female reproductive cycle. In contrast, FAM is much more likely to foster the critical responsible attitude. This is because, when using FAM, a couple does not lose sight of the natural biological function and operation of a woman's healthy reproductive system. Conception is not likely to occur unless a couple intentionally breaks "the rules" and thus FAM-based family planning necessarily confronts a couple with the question whether they are willing and able to care for a child.

Given the widespread lack of awareness of FAM, success of a FAM-based approach still would hinge on a multi-faceted campaign to educate women

Committee expressly stated that family planning "requires scrupulous use of the best methods - not some of the time but all of the time." The Best Intentions, supra note 202, at 138. The evidence points toward FAM as being the "best method." Reasons exist why an IOM committee would fail to recognize FAM as a feasible and effective solution - reasons primarily tied to financial conflicts of interest and deficiencies of medical school curricular content. See Weschler, supra note 182, at 5-7. An explanation for why the Committee would offer a flawed analysis does not, however, cure the flaws in the analysis. 
and men - a process that could have been initiated as part and parcel of implementation of the preventive services mandate. But the likelihood of success should be greater than that of the IOM contraceptive-based strategy. The message would continue to endorse the benefits associated with family planning, but without concerns about serious health risks and unpleasant side effects and without requiring a radical change in core family planning practices and beliefs. For several reasons, then, the contraceptive-based goal and strategy of the IOM Committee are grounded in questionable logic, and the cumulative effect of the many shortcomings of The Best Intentions greatly undermines its value as evidentiary support for CPSW's recommendation to include contraceptives in the coverage mandate for women's preventive services.

\section{AN IDEOLOGY WITHOUT EVIDENTIARY SUPPORT CANNOT TRUMP RELIGIOUS LIBERTY}

In-depth scrutiny of the evidence relevant to the compelling interest prong of the government's burden under RFRA reveals significant shortcomings. The government must show that additional religious exemptions to the contraceptive mandate will impair the interest in providing insurance coverage for preventive health care services needed for women to maintain good health. The statutory text ties the content of the services to be included in the mandate to assessments made by expert advisors, and HHS explained that this assessment would include a rigorous risk/benefit study to ensure that mandated services in fact promote women's health and are not merely popular services. The risk/ benefit assessment would be conducted by expert advisors, but HHS would have a role: that of ensuring the assessment satisfied the expected standard. HHS delegated the assessment task to the Institute of Medicine and, in the RFRA litigation, the government has relied predominantly on the 2011 IOM Report to satisfy its burden of proof.

Scrutiny of the 2011 IOM Report in relation to the recommendation to include contraceptive services confirms both criticisms of the dissenting CPSW member and BCPI's characterization that the government's case "is based on a chain of presumed causes and effects, and the evidence supporting each link is attenuated, ambiguous, disputed, or non-existent." 292 In preparing the 2011 IOM Report, CPSW failed to consider all the relevant evidence. In particular, CPSW ignored studies and decades of experience which cast considerable doubt on the premise that contraceptive use results in effective family planning; ignored recent peer-reviewed scientific studies that highlight significant and growing concerns about the risk of serious adverse health consequences associated with using hormonal contraceptives - especially the newer, longer-lasting options that the government hopes women will embrace in increasing numbers; and ignored FAM, a highly effective and

292. BCPI Brief, supra note 79, at 6 . The BCPI brief similarly questions the logic of government's claim that the mandate advances gender equality. See supra note 90. 
clearly safer approach to family planning, and an approach more consistent both with family planning methods currently embraced by many and with genuine concern for women's health. CPSW also uncritically relied on the work of ACOG and the 1995 IOM publication, The Best Intentions. The ACOG professional guidelines are evidence only of a willingness of ACOG members to prescribe FDA approved hormonal contraceptives to women willing to consent to the risk. And The Best Intentions is riddled with analytical shortcomings: omission of consideration of serious health risks, an unduly exaggerated view of the "problem of unintended pregnancy" and its consequences, and goals and strategies grounded in questionable logic and which, again, are inconsistent with family planning methods currently embraced by many and inconsistent with genuine concern for women's health.

Upon scrutiny, the shortcomings of CPSW's methodology and CPSW's uncritical reliance on other work with obvious logical shortcomings, justifies the critique of the dissenting opinion to the 2011 IOM Report that the CPSW recommendations reflect but subjective preferences and "determinations filtered through a lens of advocacy." 293 That is, they reflect a pre-ordained

293. The IOM panel was comprised overwhelmingly of persons with records of being tied to or substantially supportive of organizations dependent on or fully supportive of a contraceptive-based approach to family planning, e.g., Planned Parenthood and the National Abortion Rights Action League. The organization Americans United for Life has detailed ties between several members of CPSW and Planned Parenthood and other openly pro-abortion organizations. See The Con: HRSA guidelines and the Institute of Medicine, accessible at http:/ / www.aul.org/the-con-hrsa-guidelinesand-the-institute-of-medicine/ (explaining as follows: "According to her biography, Dr. Paula Johnson "served for many years on the board of Planned Parenthood League of Massachusetts and chaired the board from 1997-1998." See http://www.bphc.org/boardofhealth/boardmembers/Pages/Home.aspx (last visited Sept. 27, 2011); Dr. Magda Peck served as chair and vice-chair of the Board of Directors Planned Parenthood of Nebraska Council Bluffs (now Planned Parenthood of the Heartland) from 2006-2009. See http://www4.uwm.edu/secu/news_events/sph-dean/Peckcv.pdf (last visited Sept. 27, 2011); Dr. Carol Weisman served as a member of the Affiliate Medical Committee of Planned Parenthood of Maryland from 1993-1997 and was a member of the Board of Directors of Planned Parenthood of Maryland from 1978-1984. See http://www.pennstatehershey.org/c/document_library/get_file?folderId=229089\&name=DLFE-25907.pdf (last visited Sept. 27, 2011). Dr. Francisco Garcia has worked with the International Planned Parenthood Federation See http://orwh.od.nih.gov/about/Garcia\%20(updated\%202-18-10)-edited\%20clean\%20copy.pdf (last visited Sept. 27, 2011); Dr. Paula Johnson serves on the board of the Center for Reproductive Rights, an organization which seeks to expand abortion access. See http://www.bphc.org/boardofhealth/boardmembers/Pages/Home.aspx (last visited Sept. 27, 2011); Dr. Claire Brindis is a co-founder of the Bixby Center for Global and Reproductive Health. The Bixby Center provides abortion training and runs initiatives designed to increase and expand abortion services. See http://bixbycenter.ucsf.edu/research/abortion.html (last visited Sept. 27, 2011). Dr. Brindis also chaired the Population, Family Planning and Reproductive Health Section (PRSH) of the American Public Health Association. The PRSH has a "task force" dedicated to abortion. See http://www.apha.org/membergroups/sections/aphasections/population/benefits/taskforces.htm (last visited Sept. 27, 2011); Dr. Angela Diaz has served as a Board Member for the Physicians for Reproductive Choice and Health. See http://www.prch.org/about-board-directors (last visited Sept. 27, 2011); and Dr. Alina Salganicoff has worked as a trainer and counselor for CHOICE, "a Philadelphia-based reproductive health care advocacy organization." See http://www.kff.org/womenshealth/upload/Speaker-Biographies-Women-and-Health-Care-ANational-Profile.pdf (last visited Sept. 27, 2011).) AUL also has pointed out that nearly every invited presenter urged the inclusion of all FDA-approved contraceptives in the mandate. Id. (accessed January 16, 2013). 
perspective or ideology that simply equates contraceptives with family planning.

Family planning is important for women's health, but the evidence does not support the proposition that contraceptives are necessary for safe and effective family planning, and thus does not support the proposition that contraceptives are necessary for women's health. The ideology that equates contraceptives with family planning is held by many who genuinely seek to promote women's interests. Nonetheless, it is an ideology that tends to overshadow attention to genuine women's health - because it is a perspective that renders it inevitable that analysis of other effective and undoubtedly safer family planning methods will not occur, and that tends to preclude recognition of the fact that unnecessarily encouraging women to use drugs and devices that pose very serious health risks - day in and day out for decades logically cannot be a strategy that genuinely promotes women's health. ${ }^{294}$

As such, it becomes clear that government has not yet shouldered its burden under RFRA, and it is difficult to see how the government will be able to as the litigation plays out in the future. Given the many and varied shortcomings of the 2011 IOM Report and the key evidence relied on by CPSW in preparing the report (and by HHS in adopting the CPSW recommendation), the government's evidence lacks probative and persuasive value. The government's evidence suggests that additional religious exemptions to the contraceptive mandate will not significantly impact women's health generally, and does not suggest that exemptions as to contraceptive coverage will significantly undermine Congress's purpose in enacting the general women's preventive services mandate. The government's evidence suggests that ideology rather than sound empirical investigation was the driving force behind the mandate and, as to a federal law that substantially burdens the exercise of religion, promotion of an ideology will not suffice. ${ }^{295}$

294. Cf. Erika Bachiochi, Embodied Equality: Debunking Equal Protection Arguments for Abortion Rights, 34 HARV. J.L. \& PUB. POL'Y 889 (2011) (touching on the idea that concern for genuine women's health has been overshadowed by ideology as part of an analysis showing how leading prochoice feminist legal literature has made the wombless male body the norm, and thereby has promoted cultural hostility toward pregnancy and motherhood; and arguing that prolife feminism better promotes women's equality because it does not embrace the claim that equality requires women to deny their fertility and reject their children).

295. Moreover, the pervasive nature of the influence of ideology in the rulemaking process raises meritorious questions as to whether the mandate would survive a challenge under the Administrative Procedure Act. Courts via "hard look" judicial review may encourage better policy making by ensuring that agencies have used a process reflecting reasoned decision making; they may demand that the agency has demonstrated through its explanation of the rule and the administrative record supporting the rule, that it has examined the relevant data and articulated an explanation that makes a rational connection between the facts found and the choice made. See Motor Vehicle Manufacturing Ass'n v. State Farm Mutual Automobile Ins. Co., 463 U.S. 29 (1983). Agency rules also can be set aside if the rulemaking process demonstrates the agency approached the task with an irretrievably closed mind. See, e.g., United Steelworkers of America v. Marshall, 647 F.2d 1189 (D.C. Cir. 1981). 